\section{Seismic Stability of Wide-Flange Steel Columns Interacting with Embedded Column Base}

\section{Connections}

\author{
Hiroyuki Inamasu'; Amit M. Kanvinde², Member ASCE ; Dimitrios G. Lignos ${ }^{3}$, Member ASCE
}

Abstract: The rotational flexibility of column base connections is commonly assumed to be detrimental to the seismic response of steel Moment Resisting Frames (MRFs) because it increases story drift demands and promotes soft-story formation by lowering the point of inflection, thereby exacerbating the moment demand at the first-story column top end. However, recent experimental research indicates that wide-flange steel columns with flexible boundary conditions may show enhanced response because base connection flexibility delays the plastic hinge formation and local buckling progression within the column cross-section near the base. Local buckling greatly reduces the lateral and torsional restraint at the column ends such that the delay in local buckling also delays member instabilities, which often control the deformation capacity of wide-flange steel columns. This effect is examined parametrically through 2160 Continuum Finite Element (CFE) simulations validated against physical experiments. Parameters interrogated include the applied axial load ratio, the column length, and the lateral loading protocol for the column sections, along with five levels of column base connection flexibility. The results indicate that base connection flexibility has a significant (and positive) influence on key aspects of column response, including: (1) lateral deformation capacity, which is on average $40 \sim 50 \%$ greater for a realistic value of flexibility, relative to a fixed-base condition, and (2) residual column axial shortening, which is important from the standpoint of retrofit and reparability (a 30-60\% decrease). These benefits are more pronounced in cyclic (versus monotonic) loading histories and for members with cross-sections more prone to out-of-plane instability.

\footnotetext{
${ }^{1}$ Doctoral Assistant, Department of Architecture, Civil and Environmental Engineering, École Polytechnique Fédérale de Lausanne (EPFL), Station 18, Lausanne 1015, Switzerland

${ }^{2}$ Professor, Department of Civil and Environmental Engineering, University of California, Davis, CA, 95616, USA

${ }^{3}$ Associate Professor, Department of Architecture, Civil and Environmental Engineering, École Polytechnique Fédérale de Lausanne (EPFL), Station 18, Lausanne 1015, Switzerland
} 
22 The implications of these findings are outlined for existing buildings as well as prospective design 23 methodologies. Limitations are discussed.

24 Keywords: Embedded Column Bases; Wide Flange Steel Columns; Boundary Conditions; Column 25 Stability; Axial Shortening; Lateral-Torsional Buckling; Continuum Finite Element Simulation

\section{Introduction}

28 Steel Moment Resisting Frames (MRFs) in seismically active regions in the United States (AISC 2016a) 29 and elsewhere (e.g., BCJ 2016; CEN 2004) are designed to concentrate plastic deformations in the beams 30 while the columns should remain elastic under seismic shaking. To accomplish this, beams are designed for 31 reduced seismic loads (i.e., using of the strength reduction factor, R), while column design is based on a 32 combination of capacity design principles (i.e., Strong Column Weak Beam), as well as amplified seismic 33 loads (i.e., the overstrength factor, $\Omega_{0}$ ). The intent of this design practice is to discourage the development 34 of soft-story mechanisms (Figure 1a) that concentrate yielding within one story, and to promote a full35 building yielding sway mechanism (Figure 1b) in which beams from all stories participate. Despite its intent, 36 this practice cannot eliminate plastic hinges in first-story columns in all cases, due to the following: (1)

37 plastic hinges at the lower ends of first-story columns are a kinematic necessity for the formation of a full-

38 frame mechanism as shown in Figure 1b, and (2) Strong Column Weak Beam design assumes a first mode 39 response to determine the column strength demands; this is often violated, especially in mid- to high-rise 40 frame buildings (Elkady and Lignos 2014, 2015b; Gupta and Krawinkler 1998) in which higher-mode 41 response is likely to trigger soft story collapse mechanisms either in the first or upper stories of a steel MRF.

42 In either case, the cyclic inelastic response of columns is of concern for two reasons. First, the plastic hinges 43 weaken the column ends, rendering it susceptible to Lateral Torsional Buckling (LTB); this is particularly 44 concerning since unlike beams, columns cannot be conveniently braced against LTB. Furthermore, steel 45 MRF columns often carry substantial axial force and are in the vertical load path, such that their potential 46 loss of axial load carrying capacity has severe implications for global collapse. As a result, the cyclic 47 inelastic response of columns, with an emphasis on their cross-sectional and lateral-torsional stability and 
the ensuing loss of lateral and vertical load carrying capacity has recently gained attention in research

49 (Elkady and Lignos 2018a; b; Fogarty et al. 2017; Fogarty and El-Tawil 2016; Ozkula et al. 2017; Suzuki

50 and Lignos 2015, 2018a; Wu et al. 2018). This research has yielded new information regarding the influence

51 of various parameters (e.g., cross-sectional properties including width-thickness ratios, load histories, and

52 boundary conditions) on the column's hysteretic response, deformation capacity, and lateral-torsional

53 stability. A particularly interesting finding is that boundary conditions (specifically rotational fixities at the

54 top and the bottom of the column in the major-axis direction) have a strong influence on lateral-torsional

55 stability, and ultimately, the deformation capacity of the column. As an example, fixed-flexible columns

56 tested by Elkady and Lignos (2018a) showed deformation capacities roughly $20-30 \%$ higher than their

57 fixed-fixed counterparts - a significant difference in deformation capacity. As noted by Elkady and Lignos

58 (2018), the physical mechanisms underlying this effect are somewhat complex and unintuitive. Specifically,

59 the rotational flexibilities at the member ends control the moment diagram, which affects the plastic rotation,

60 and more importantly, its apportionment between the top and bottom plastic hinge regions. In turn, the

61 accumulated in-plane (major axis) plastic rotation at each plastic hinge region impacts its ability to provide

62 out-of-plane, i.e., lateral-torsional restraint. Thus, the cyclic deformation capacity (corresponding to LTB)

63 is controlled by highly nonlinear interactions between the hysteretic response of the plastic hinge regions

64 (both in- and out-of-plane), the lateral stiffness of the column cross-section, and its resistance to lateral-

65 torsional buckling.

66 From the standpoint of steel MRF design and collapse behavior, the above findings are relevant for two

67 reasons: (1) moment frames are usually designed (and simulated) assuming an ideally fixed base boundary

68 condition, entirely disregarding the effect of base flexibility on the MRF seismic response, and (2) recent research (Barnwell 2015; Grilli et al. 2017; Grilli and Kanvinde 2017; Rodas et al. 2017) has shown that even if designed as fixed, column bases of various types have considerable rotational flexibility. Zareian and Kanvinde (2013) have examined the "first-order" implications of such simplifications. These pertain to

72 redistribution of moments in the first-story column due to the unanticipated base flexibility, leading to 
73 moment amplification at the column top and the formation of a soft story. However, these studies do not 74 consider the effect (discussed above) of base flexibility on out-of-plane stability of the column and 75 associated change in deformation capacity - both of which are closely linked to system collapse (Lignos 76 and Krawinkler 2012). Disregarding this consequential effect is problematic, especially as current guidelines 77 for building performance assessment (FEMA 2009; PEER-TBI 2017) are heavily dependent on accuracy in 78 collapse simulations.

79 Motivated by the above, this study presents parametric Continuum Finite Element (CFE simulations) to 80 quantitatively examine the effect of boundary conditions (specifically base flexibility) on the cyclic inelastic 81 response of wide flange steel columns; particularly their deformation capacity, axial shortening and lateral82 torsional stability. The former is associated with a member's ductility, while the axial shortening and lateral 83 torsional stability are associated with the member stability. The study focuses on columns that respond as 84 per the intent of current "strong-base-weak-column" practices (AISC 2016a), such that all inelastic response 85 is concentrated in the column section, rather than the base connection. The main scientific basis of this study 86 is a series of 2160 3-dimensional (3-D) CFE simulations that evaluate the following parameters: (1) column

87 base rotational stiffness, (2) axial load ratio, (3) column length, (4) column cross-section, and (5) applied 88 lateral loading protocol. The simulations use methodologies and calibration procedures that have been 89 extensively validated against physical testing previously conducted by Elkady and Lignos (2015a, 2018a, 90 2018b), and the parameter ranges represent realistic values consistent with common design and construction 91 practice.

92 The paper begins by summarizing recent research on columns, as well as column base connections that 93 motivates this study. This is followed by a discussion of the FE simulations, including modeling 94 assumptions/procedure, simulation matrix, and results. The main discussion of the results focuses on the 95 interplay between boundary conditions and column properties to affect the cyclic deformation response and 96 lateral-torsional stability of steel columns. A collateral finding (which pertains to the effect of boundary 97 conditions on axial and lateral residual deformations of the columns) is also discussed; this is important 
from the standpoint of post-event repair/retrofit strategies. The paper then examines the implications of this study in the context of improvements to design practice, and outlines future work necessary to achieve these improvements.

101

\section{Full-scale Tests on Embedded Column Bases and Wide-Flange Steel Columns}

Column base connections in steel MRFs may be broadly classified as being of the exposed base plate type (in which anchor rods attached to a base plate transfer flexure - see AISC Design Guide One (Fisher and Kloiber 2006)), or the embedded type, in which the lower portion of the steel column is embedded into a concrete footing. The former are usually feasible in low-rise MRFs where bases are assumed pinned, whereas the latter are more prevalent in mid- to high-rise MRFs (to carry large base moments), or when the bases are notionally fixed. Consequently, the latter (i.e., embedded type) connections are of interest in this study. Recently, Grilli et al. (2017) tested six large-scale specimens of embedded column bases subjected to combinations of axial (to represent gravity) and cyclic lateral (to represent seismic) loading. The specimens featured details common to United States construction practice (see Figure 2), including an embedded base plate at the bottom of the embedment, and a stiffener plate at the top of the connection to transmit axial compression. Referring to Figure 2, all specimens were tested as cantilever columns designed to be stronger than the connections, such that only connection failure modes were obtained. Referring to Table 1, which summarizes the test matrix from Grilli et al. (2017), a range of parameters (axial load ratio, column cross-section, and embedment depth) were interrogated. A similar experimental study was conducted by (Richards et al. 2018); albeit these specimens with somewhat shallower embedment were representative of exposed base connections with an overtopping slab - less relevant to the goals of this study,

119 which focuses on bases with high notional rigidity.

Grilli et al. (2017) reported various failure modes (including concrete bearing failure ahead of the flanges and panel zone cracking, or uplift failure). Additionally, it was noted that all tested specimens showed 
123 denoted $\beta$. As determined by Grilli and Kanvinde (2015), this degree of flexibility is of approximately the 124 same magnitude as the rotational flexibility at the top of the first story column, which is the result of 125 appropriately designed beams and the column above. This has two implications, relative to the fixed base 126 assumption: (1) the point of inflection in the first story column moves downwards increasing moment 127 demands at the column top end, while reducing moment demands at the bottom, and (2) the story drift 128 increases appreciably (by approximately 30-40\% - Grilli et al. (2017)). Zareian and Kanvinde (2013) 129 examined these effects, and their influence on the system-level steel MRF response. However, this 130 examination is restricted to in-plane effects and the associated frame response. The focus in this study is on 131 out-of-plane effects - as illustrated schematically in Figure 3 at a given lateral drift demand in cases that the 132 column base flexibility is considered (see Figure 3b) versus the idealized fixed column base (see Figure 3a). 133 More specifically, the effect discussed in point (1) above results in a lowered inflection point, and 134 consequently, a lower bending moment at the first story column base. In turn, this delays the formation of a 135 plastic hinge at the column base, relative to the fixed-base configuration. It is well-known (e.g., Ozkula et 136 al. 2017), that albeit the plastic hinge itself is associated with in-plane rotations, steel material inelastic 137 behavior within the plastic hinge, limits its ability to restrain out-of-plane buckling modes such as LTB. As 138 a result, despite their higher initial stiffness, columns with fixed bases are susceptible to local buckling at 139 lower deformations as compared to similar columns with base rotational flexibility. In fact, a similar effect 140 was noted previously by Elkady and Lignos (2018b), in which the flexibility at the column top end (due to 141 the respective beam-to-column connection) increased the deformation capacity of the column with respect 142 to member instabilities.

143 The foregoing discussion, when considered along with the findings of Elkady and Lignos (2018a; b) 144 establishes that realistic values of column base flexibility have the potential to significantly impact the 145 response (specifically the propensity for LTB) of wide-flanged columns in steel MRFs. The next section 146 parametrically examines this effect through CFE simulations on a range of columns and base conditions that 147 are realistic with respect to current United States design practice. 
149 Continuum Finite Element Model for Steel Columns Interacting with Embedded Column Bases

150 The seismic stability of wide-flange steel columns interacting with concrete footings is investigated by 151 means of CFE simulations. This section discusses the specifics of the CFE model including its validation. 152 This involves two steps. First the CFE simulations are validated rigorously by leveraging unique 153 experimental data from recent full-scale tests on wide flange steel columns (Elkady and Lignos 2018a) and 154 embedded column base connections (Grilli et al. 2017). Once validated, these are used to parametrically 155 comprehend the physical phenomena discussed earlier.

\section{Finite element model for wide flange steel columns}

158 The steel wide-flange column CFE model is developed in the commercial finite element analysis software 159 ABAQUS (Version 6.14-1) (ABAQUS 2014) based on the modeling recommendations summarized in 160 Elkady and Lignos (2015a, 2018a). Briefly, the CFE model consists of shell elements and considers material 161 nonlinearity through a multiaxial plasticity constitutive law (Lemaitre and Chaboche 1994; Voce 1948) 162 calibrated to uniaxial cyclic round coupon tests as discussed in Sousa and Lignos (2018). Residual stresses 163 due to hot-rolling are considered as discussed in Young (1972). Local and member instabilities are triggered 164 by assigning geometric imperfections that are within the allowable manufacturing limits (AISC 2016b; 165 ASTM 2017). The CFE modeling methodology is validated against experimental data from wide-flange 166 steel columns under multi-axis (i.e., lateral or bilateral coupled with axial) cyclic loading (Elkady and 167 Lignos 2018a). Table 2 summarizes key features of test specimens considered for the CFE model validation 168 including the applied column end boundary conditions, the applied constant compressive axial load ratio $(P$ 169 is the applied axial load; $P_{y}=R_{y} f_{y} A ; R_{y}$ is the ratio of the expected yield stress to the nominal yield stress, $f_{y}$

170 is the nominal yield stress, and $A$ is the cross-sectional area of the column) and the corresponding member 171 slenderness, $L_{b} / r_{y}$ ( $L_{b}$ and $r_{y}$ are the unbraced length and the radius of gyration about the column cross172 section's weak-axis, respectively). 
173 Figures 4 and 5 illustrate comparisons of the column end moment, $M_{\text {base }}$ versus the column drift, $\theta$ defined

174 as the lateral displacement at the column top end over the actual column height, $\left(L^{\prime}=L-\delta_{v}\right.$, in which, $L$ is

175 the original column length and $\delta_{v}$ is the vertical displacement, if any), the evolution of the column axial

176 shortening, respectively, obtained from the test results and CFE simulations. The second order moment, i.e.,

177 due to $P-\triangle$ effects, has been subtracted in all cases. The agreement between the test results and the CFE

178 models across the boundary conditions, the unbraced length and the applied compressive axial load ratio

179 indicates that the CFE models are able to reproduce the relevant aspects of physical response with high

180 fidelity. As discussed by Elkady and Lignos (2018b), similar agreement between tests and CFE results is

181 also noted between observed failure modes, such as local and lateral torsional buckling, and the 182 deformations associated with them.

\section{Base flexibility in column end boundary conditions}

185 The CFE model is further refined to assess the influence of the column base flexibility on the overall stability 186 of the steel column. The boundary conditions reflect those common in steel MRFs as shown schematically

187 in Fig. 6. In particular, the column base flexibility is considered with an elastic rotational spring on the basis

188 of the assumption that conventional column base design (AISC 2016a), which requires the base connection

189 to be stronger than the column, results in plastic hinging in the column section above the foundation. The

190 column base flexibility is deduced from full-scale ECB experiments (Grilli et al. 2017). These values are

191 summarized in Table 1. The remaining degrees of freedom at the base are idealized as fixed.

192 Referring to Fig. 6, the column top end boundary conditions also require further attention to accurately

193 capture structural response. In particular, a rotational spring is assigned with respect to the $y$-axis that

194 characterizes the in-plane rotational stiffness of the girders intersecting the column by considering a strong 195 column weak beam (SCWB) ratio of 1.3 that satisfies the capacity design requirements as per AISC (2016a)

196 and CEN (2004); this spring considers the potential inelastic behavior of the girders. The out-of-plane 197 flexibility due to typical shear tab beam-to-column connections (Liu and Astaneh-Asl 2000, 2004) and the 
torsional resistance of the girders is idealized with a rotational spring assigned with respect to the $x$-axis, which is characterized by a trilinear hysteretic behavior as shown in Fig. 6. Finally, the torsional resistance due to bending of the shear tab plate, the torsional resistance of the second story column and the weak-axis bending resistance of the girders is aggregated into a third spring that is assigned at the column top end with respect to the $z$-axis. Specifically, the contributions of these three components is combined into a drift203 dependent linear behavior. This behavior is inferred from experimental findings by Lignos et al. (2010) and 204 Zhang and Ricles (2006) that represent typical response of fully restrained beam-to-column connections 205 with Reduced Beam Sections (RBS).

Prior experiments on fully-restrained beam-to-column connections with deep columns (Chi and Uang 2002; Zhang and Ricles 2006) of similar sizes as the ones examined herein suggest that such columns experience torque demands after the local buckling formation within the RBS region. Referring to Fig. 7, this is attributed to the eccentricity $e_{x}$, which is introduced after local buckling initiation. Although the CFE model 210 does not consider the full-frame, the aforementioned demands are still considered in the present study 211 through a torque force - lateral drift relationship that is established on the basis of mechanics-based 212 equations and experimental observations (Chi and Uang 2002; Lignos et al. 2010; Lignos and Krawinkler 213 2012; Zhang and Ricles 2006). This relationship is shown in Fig. 6. Referring to Fig. 7, Chi and Uang (2002) 214 proposed the equation to estimate the torque force demand on the column, $T$ :

$$
T=F_{y, R B S} b_{f, R B S} t_{f, R B S}\left(e_{x} \cos \theta_{R B S}+e_{y} \sin \theta_{R B S}\right)
$$

$215 F_{y, R B S}, b_{f, R B S}, t_{f, R B S}$ are the yield stress, flange width, flange thickness of the RBS region, respectively. $e_{x}$ and $216 e_{y}$ are the eccentricities of the beam flange force $(F)$ due to beam LTB along each major axis; $\theta_{R B S}$ is the 217 inclined angle of beam flange force due to beam LTB. All parameters except for $e_{x}$ can be obtained from 218 the geometry of beam/column and material properties of the beam; the $e_{x}$ value in this study was deduced 219 from the tests conducted by Zhang and Ricles (2006) in which the floor slab is also considered. Test results 220 suggest that beam instability is induced at $2 \%$ lateral drift demand. The quantity $e_{x}$ attains a value of $10 \%$ 221 of the beam width at a lateral drift demand of 4\%. The value of $e_{x}$ increases while the local buckling 
222 progresses within the RBS region. This relation is expressed through a linear function between the torque 223 force-column drift relation. Two points are considered to establish this relationship (zero torque force at $2 \%$ 224 and deduced torque force at $4 \%$ ).

226 Parametric Finite Element Matrix

227 A parametric finite element study is established to assess the effect of column base flexibility on the overall 228 steel column stability based on the proposed CFE model discussed earlier. Several parameters are 229 interrogated. In particular, the column length covers the typical range of first story steel MRF columns (i.e., 2303 to 6 meters). The employed cross-sections (18 in total) are shown in Fig. 8. Although the majority of these 231 columns are within the limits of highly ductile members as per AISC 341-16 (AISC 2016a), moderately 232 ductile cross-sections are also considered. The applied compressive axial load ratio, $P / P_{y}$ representing the 233 gravity-induced axial load ratio that a first story steel MRF column experiences ranges from 5\%, 20\%, 35\% 234 and 50\%. This range is deemed to be rational for low to high-rise steel MRFs designed in seismic regions 235 (Suzuki and Lignos 2014, 2018b). Owing to the emerging need for data that characterize the monotonic 236 behavior of structural components (Hamburger et al. 2016; Krawinkler 2009; Lignos et al. 2018), a 237 monotonic lateral load is considered in addition to a standard symmetric lateral loading history (Clark et al. 238 2002). Finally, the considered cases are analyzed for various levels of column base flexibilities. Embedded 239 column base experiments (Grilli et al. 2017) suggest that the "actual" flexibility of a column base connection 240 designed to be stronger than the column may be assumed to be $\beta /(E I / L)=5 \times(L / 4.0)(L$ in meters) (in 241 which $E$ is the modulus of elasticity of the steel material, $I$ and $L$ are the cross-sectional moment of inertia 242 and member length of the column, respectively). This is considered to be the base case in the parametric 243 CFE matrix, since it represents the most likely physical response. Supplementary parametric study 244 simulations with base flexibilities $75 \%$ and $50 \%$ of the base case are also considered to examine the 245 sensitivity of the column response to the base flexibility. The pinned column base is also considered for 246 reference. 


\section{General observations of physical response}

250 This section presents key observations of the influence of the column base flexibility on the overall column 251 stability under cyclic loading, based on the parametric CFE study outlined in the previous section. The 252 discussion is facilitated by a comparison between the ideally 'Fixed' and 'Actual' case for a W24x146 253 column subjected to $P / P_{y}=20 \%$, which is representative of all CFE simulations. Referring to Fig. 9a, the 254 elastic stiffness of the column is reduced due to the actual flexibility of the column base. This can be 255 explained by the elastic stiffness $K^{*}$ equation (in $M_{\text {base }}-\theta$ relation) that considers all the flexibility 256 contributions of a column member. The equation is derived by idealizing that the steel column is supported 257 by two elastic rotational springs at each end boundary,

$$
K^{*}=\frac{M_{\text {base }}}{\theta}=\frac{6 E I}{L} \frac{\frac{2(E I / L)}{K_{\text {top }}}+1}{\left(\frac{12(E I / L)^{2}}{K_{\text {top }} \beta}+\frac{4(E I / L)}{K_{\text {top }}}+\frac{4(E I / L)}{\beta}+1\right)+\frac{12(E I / L)}{G A_{w} L}\left(\frac{E I / L}{K_{\text {top }}}+\frac{E I / L}{\beta}+1\right)}
$$

258 In which, $A_{w}$ is the cross-sectional area of the column web; and $G$ is the elastic shear modulus; $K_{\text {top }}$ and $\beta$ 259 are the equivalent rotational stiffness of the springs at the column top and bottom, respectively; $K_{\text {top }}$ may be 260 deduced by the respective members connecting to the column top end (as discussed before by referring to 261 Fig. 6), while $\beta$ may be deduced based on the column base connection detailing as discussed in Grilli and 262 Kanvinde (2015). Typical values for this quantity are listed in Table 1 for both shallow (W14) and deep 263 (W18) column cross-sections. The CFE simulations suggest that although the elastic stiffness $K^{*}$ decreases, 264 the onset of the local buckling near the column base occurs at a larger drift ratio, thereby delaying the cyclic 265 deterioration in the member's flexural strength and stiffness.

Referring to Fig. 9b, the inflection point is at $70 \%$ and $60 \%$ of the column height for the 'Fixed' and 'Actual' cases, respectively. Although the inflection point of the 'Fixed' case is at a higher elevation than that of the 'Actual' case in the elastic regime, it moves downwards more rapidly due to the early onset of local buckling in the former than the latter, thereby increasing the flexural demands at the column top end. It is noteworthy 
271 is at $45 \%$ and $55 \%$ of the member height, respectively.

272 The column base flexibility has a significant effect on the local buckling-induced column axial shortening

273 as shown in Fig. 9c. In particular, the column axial shortening is appreciably reduced at a given drift level.

274 For instance, at a $2 \%$ drift angle, typically associated with design basis seismic events, column axial 275 shortening of the 'Actual' case is almost 50\% less than the ideally 'Fixed' case. This has direct implications 276 in the steel column reparability in the aftermath of earthquakes (Cravero et al. 2018) as it can be seen from

277 Fig. 9d that shows the extent of local buckling near the column base for each one of the two considered

278 cases. The total member rotation is disaggregated in Fig. 10 both for the fixed and Actual case. In the latter 279 (Fig.10b), the column base flexibility reduces the accumulated plastic deformation in the column itself.

\section{Influence of Column Base Flexibility on Base Moment vs Column Drift Response}

282 Figures 11a and 11b show the load-deformation response (column base moment versus column drift) from 283 CFE simulations of a monotonic load case (W24x146, $L=4500 \mathrm{~mm}, P / P_{y}=20 \%$, Monotonic loading) and a 284 cyclic load case (W24x146, $L=4500 \mathrm{~mm}, P / P_{y}=20 \%$, Cyclic loading), respectively. The purpose of these 285 plots (which are qualitatively representative of all CFE simulations outlined in the previous section) is to schematically illustrate key quantities retained from the CFE for the purpose of column performance assessment. These quantities have been determined to strongly influence the seismic performance and global collapse of steel MRFs (Elkady and Lignos 2014, 2015b; Ibarra and Krawinkler 2005, 2011; Lignos et al. 2011, 2013). Referring to Figs. 11a and b, these performance indicators include: (1) the peak moments $M_{\max }$ $\left(M_{\max }^{*}\right)$ where the term $M^{*}{ }_{\max }$ in the parentheses denotes the peak (considering both directions) of the cyclic envelope, whereas the term $M_{\max }$ denotes the peak of the monotonic backbone (the two are different due to the influence of loading history and material cyclic hardening), (2) the deformation $\theta_{\max }\left(\theta^{*}{ }_{\max }\right)$, corresponding to the attainment of these peak moments, and (3) the "post-capping" plastic rotations $\theta_{p c}\left(\theta_{p c}^{*}\right)$ corresponding to the rotation at which the moment carrying capacity is lost subtracted by $\theta_{\max }\left(\theta^{*}{ }_{\max }\right)$, indicating high potential for structural collapse (Ibarra and Krawinkler 2011). In cyclic loading, both 
positive and negative excursions are considered to obtain these values. Figures 12a-c show monotonic curves for three different cross-sections (W36x529, W21x147, and W21x101), which are selected from the CFE simulation matrix outlined in the previous section, whereas Figures 13a-c show the first-excursion cyclic envelopes (i.e., a curve connecting the extreme points of each cyclic excursion) for the same three columns. In each case, the curves are plotted for four levels of base fixity ('Fixed', 'Actual', 75\% 'Actual', $50 \%$ 'Actual'). The cross-sections are sampled from the test matrix to examine general trends across the web slenderness ratios $\left(h / t_{w}\right)$. Referring to Figures 12 and 13, the following observations may be made:

- Referring to Figs $12 \mathrm{a}-\mathrm{c}$, it is readily apparent that as the cross-section local slenderness increases, the effect of base flexibility on the response increases as well. Specifically, for the W36x529 $\left(h / t_{w}\right.$ $=21$, highly ductile), the curves from the four base fixities differ mainly (as expected) in the elastic region, but are virtually coincident as the response transitions to yielding, followed by attainment of the peak due to LTB, and post-peak response. As the local slenderness increases (Figures 12b and c), the curves from the different flexibilities slightly diverge. For the most slender section (W21x101), local buckling followed by LTB occurs at the end of the elastic phase which is longer for the more flexible base connection.

- Referring to Figures 13a-c, the effect of flexibility on the cyclic "first-excursion" envelope curves is significantly more pronounced as compared to the monotonic cases. For each of the three crosssections examined in this figure, the drift $\theta^{*}{ }_{\text {max }}$ corresponding to the peak increases as the column base flexibility increases. It is important to point out that this is not merely an artifact of the elastic stiffness being lower for higher base flexibility - since LTB typically follows after local buckling and it is attained well after yielding. More specifically, for each of the three sections, the increase in $\theta^{*}{ }_{\max }$ with respect to flexibility is mostly attributed to a delay in local buckling in the post-yield phase. Referring to the phenomenology of response discussed previously (see Figure 3), recall that LTB occurs when the torsional fixity at the ends is compromised due to formation of plastic hinges. As evidenced by Figures 13a-c and visual observations of response (e.g., Elkady and Lignos 2018a; 

subsequently the loss of torsional fixity at the ends, resulting in improved column performance. pronounced for the rotation at peak, $\theta_{\max }\left(\theta_{\max }^{*}\right)$. In contrast, the peak moment, $M_{\max }\left(M^{*}{ }_{\max }\right)$ and post-capping plastic rotation, $\theta_{p c}\left(\theta_{p c}^{*}\right)$ are relatively insensitive to the column base flexibility regardless of cross-sectional slenderness.

- Figures $14 \mathrm{a}$ and $\mathrm{b}$ plot $\theta^{*}{ }_{\max }$ for all the fixed base simulations against the ratio $L / L_{p}$ (where $L_{p}$, which is indicative of the column resistance to LTB, is determined as per AISC 2016a). This provides a quantitative baseline of the deformation capacity of the column, against which the flexible base cases may be evaluated. Referring to Figures $14 \mathrm{a}$ and $\mathrm{b}$, it is not surprising that $\theta^{*}{ }_{\max }$ decreases with $L / L_{p}$ sharply dropping as $L / L_{p}$ exceeds unity, indicating a transition from fully plastic response (attainment of $M_{p}$ ) to inelastic LTB in most cases. However, it is useful to interpret this in the context of the web slenderness ratio, $h / t_{w}$ as discussed in the next section. Figures $14 \mathrm{c}$ and $\mathrm{d}$ indicate the deformation capacity for the flexible base conditions, normalized by the corresponding values (shown in Figures 14a and b) for the fixed base conditions. Figures $14 \mathrm{a}$ and c correspond to $P / P_{y}=$ $20 \%$, whereas Figs $14 \mathrm{~b}$ and $\mathrm{d}$ correspond to $P / P_{y}=50 \%$. Referring to Figs $14 \mathrm{c}$ and $\mathrm{d}$, it is immediately apparent that (1) the base flexibility increases the deformation capacity with respect to the fixed condition, and (2) the degree of base flexibility controls this increase. More specifically, if the best estimate of base flexibility (i.e., 'Actual') is used in analysis, then the column's deformation capacity is increased, on average, by up to about $40 \%$ and $50 \%$ for $P / P_{y}=20 \%$ and $P / P_{y}=50 \%$ with $L=4500 \mathrm{~mm}$, respectively - a significant increase. Further, using a base flexibility $50 \%$ of the base estimate (i.e., $50 \%$ 'Actual') results in an even greater (on average $75 \%$ and $97 \%$ for $P / P_{y}=20 \%$ and $P / P_{y}=50 \%$ with $L=4500 \mathrm{~mm}$, respectively) increase in the column deformation capacity. Implications of this finding in the context of design and performance assessment (along with associated trade-offs) are discussed in a subsequent section. 
- The increase in deformation capacity due to the column base flexibility appears to show a positive trend with respect to $L / L_{p}$ (Figure 14c), indicating that a greater benefit is obtained for members that are more susceptible to the out-of-plane instability. This is not surprising, considering the mechanism through which enhancement of deformation capacity occurs; specifically that the flexible base conditions limit the column inelastic rotation demands, thereby delaying the loss of out-of-plane restraint. This effect is reduced when (for the given length) the cross-section itself is highly resistant to out-of-plane deformations, e.g., for $L / L_{p}<1$. No significant trend is observed with respect to the level of the applied axial load.

\section{Influence of Column Base Flexibility on Column Residual Axial Shortening}

356 Figure 15 shows the definition of column axial shortening, $\delta_{\text {axial }, \beta}$ considering the degree of column base 357 flexibility, $\delta_{v, \beta}$ with reference to the undeformed, and pinned column case $\delta_{v, p i n}$. Physical column testing 358 (Elkady and Lignos 2018a; MacRae et al. 1990; Ozkula et al. 2017; Suzuki and Lignos 2015) complemented by CFE simulations (Elkady and Lignos 2015a, 2018b; Fogarty et al. 2017; Fogarty and El-Tawil 2016) suggest that column axial shortening is a primary failure mode currently not addressed in seismic code provisions; thus recent recommendations focus on how to limit column axial shortening in the context of seismic design provisions of steel MRFs (Elkady and Lignos 2018b; Wu et al. 2018), typically resulting in a heavier column design depending on the applied compressive axial load ratio. Recent work (Cravero et al. 2018; Suzuki and Lignos 2015, 2018a) suggests that column axial shortening may control decisions associated with reparability in the aftermath of earthquakes. In this section, the considered cross-sections are sampled to examine the influence of the degree of column base flexibility on the column residual axial shortening. The discussion is based on the CFE simulations under symmetric cyclic loading histories at story drift angles of interest to the engineering profession; namely, $\theta=2 \%$ associated with a design basis seismic event (i.e., $10 \%$ probability of exceedance over 50 years) and $\theta=4 \%$ associated with a maximum considered seismic event (i.e., $2 \%$ probability of exceedance over 50 years). Referring to Figs. 16 to 18 , the

371 following observations may be made: 
- Figure 16a illustrates the strong influence of the column cross-section web local slenderness, $h / t_{w}$ on the $\delta_{\text {axial }, \beta}$. The CFE simulations indicate that at $2 \%$ drift angle column axial shortening is up to $10 \mathrm{~mm}$, if the flexibility at the base is considered. While the assumed column base flexibility increases, the quantity $\delta_{a x i a l, \beta}$ attains a value of nearly zero for the same reference drift angle. Crosssections near the current seismic compactness classification limits as per AISC (2016a) shorten considerably when idealized as fixed. However, this varies depending on the assumed degree of the column base flexibility. For instance, at a reference drift angle of $2 \%$ the steel column with $h / t_{w}=$ $38, P / P_{y}=20 \%$ and an intentional flexibility equal to $50 \%$ of the 'Actual' experiences nearly zero axial shortening compared to the ideally fixed case.

- Referring to Fig. $16 \mathrm{~b}$, the $\delta_{\text {axial }, \beta}$ is shown with respect to $L / L_{p}$ at a reference drift angle of $4 \%$. A $P / P_{y}=20 \%$ is considered in this case for three different member lengths $(L=3000 \mathrm{~mm}, 4500 \mathrm{~mm}$, $6000 \mathrm{~mm}$ ). In the range of $L / L_{p}<1.5$, columns with similar $L / L_{p}$ values (i.e., similar $r_{y}$ - radius of gyration with respect to the cross-section's weak axis - for a given column length) result in a sudden increase of the column axial shortening as highlighted by the dashed lines. This suggests that column axial shortening is mostly controlled by the respective column web local slenderness given an axial load level because this is the only variable in this case. On the other hand, if $L / L_{p}>1.5$, the column is mainly governed by out-of-plane deformation of the member, which does not result into excessive axial shortening (i.e., about $100 \mathrm{~mm}$ at $4 \%$ ) unless if the respective column utilizes a slender cross-section $\left(h / t_{w}>30\right.$ for $\left.P / P_{y}=20 \%\right)$.

- Past studies (Elkady and Lignos 2018a; b) highlighted the strong dependence of the column axial shortening with respect to the cumulative plastic rotation, the column web slenderness, $h / t_{w}$ and the applied axial load ratio, $P / P_{y}$. Figure 17 shows the column axial shortening versus the cumulative plastic rotation relation for four different cross-sections (W36x194, W21x147, W24x146, W13x221) and four different degrees of column base flexibility. The assumed column length and applied axial load ratio were $L=4500 \mathrm{~mm}$ and $P / P_{y}=20 \%$ in all cases. The figure suggests that if the elastic contribution of the considered degree of column flexibility is subtracted then the column 
axial shortening is nearly the same in all cases. However, this would occur at different lateral drift angles between cases. This indicates that the empirical equation proposed by Elkady and Lignos (2018b) may be used to compute the column axial shortening even in cases with intentional column

\section{Potential Implications for Seismic Design of MRFs}

The parametric studies and the above discussion demonstrate the effects of base flexibility on various aspects of the cyclic response of wide-flange steel columns. Although these are interesting from a scientific and physical perspective, perhaps more importantly, they have major potential implications for the seismic design and performance assessment of steel MRFs. This is due to two factors: (1) these effects are quantitatively significant, such that key performance indicators vary by as much as $40 \sim 50 \%$ (for the capping rotation, which greatly affects collapse), and $30 \sim 40 \%$ for $P / P_{y}=20 \%$ and $50 \sim 60 \%$ for $P / P_{y}=50 \%$ (for the axial shortening, which affects retrofit decisions) in the comparison between cases with ideally fixed-base and actual embedded column base flexibility; such variation/error may be considered unacceptable, (2) the physical mechanisms and interactions responsible for these effects cannot be suitably modeled through

419 frame simulations (and are complex to model even in CFE simulations), such that they are entirely 420 disregarded within the current framework for seismic design and performance assessment. Against this 421 backdrop, the following implications are noted for design and performance assessment: 
- For existing buildings, whose collapse performance is of interest (e.g., within a PEER-TBI 2017 type

424 framework) in support of retrofit or insurance decisions, incorporating the beneficial effects of base 425 flexibility may have a significant (and positive) influence on the estimated probability of collapse, since 426 the effective deformation capacity of the columns is enhanced due to this flexibility. However, this 427 should be considered early on in the design phase so as the formation of first story collapse mechanisms 428 are prevented as discussed in the subsequent bullet point.

- For prospective design methodologies, the findings of this research possibly mitigate the problems 430 commonly associated with flexible bases. Specifically, it is well understood (e.g., Zareian and Kanvinde 431 2013) that even when capacity-designed to be stronger than the column, base connections have 432 appreciable flexibility; this lowers the point of inflection in the first story column triggering a soft-story.

433 Consequently, significant expense is often required to design the connections with high degree of fixity.

434 However, the current study indicates that such behavior appears in simulations only when the beneficial 435 effects of flexibility (i.e., by delaying local buckling) are not modeled. When these effects are modeled, 436 this negative influence of base flexibility is offset by the delay in local buckling; in fact, the net response 437 is improved with respect to the fixed-base case. The implication is that in many cases, the additional 438 expense required to provide base fixity may not be necessary, and may even be detrimental from the 439 standpoint of collapse performance.

440 - With reference to the above, it is relevant to note that there is interest within the professional practice 441 and research community (Castelo et al. 2017; Rodas et al. 2016; Trautner et al. 2016) to develop base 442 connections that are not capacity designed, such that they develop some degree of plastic deformation. 443 This too is motivated by the high expense of constructing strong base connections. A primary concern 444 in developing such lower-strength, ductile connections is their flexibility and its impact on the system's 445 seismic performance (since strength and stiffness are usually correlated). The research presented herein $446 \quad$ assuages this concern to some degree. 
447

448

449

450

451

452

453

454

455

456

457

458

459

460

461

462

463

464

465 Summary and Conclusions

466 This paper presents the findings of parametric continuum finite element (CFE) simulations that investigated 467 the hysteretic response, deformation capacity, and lateral-torsional stability of wide-flange steel columns 468 469

470

- Recall that the beneficial effects of base flexibility are observed not only in the capping rotation, but also in the axial shortening. While important for retrofit decisions as indicated by a recent study (Cravero et al. 2018), assessment of axial shortening is currently not a part of established performance assessment frameworks (e.g., FEMA 2009; PEER-TBI 2017). As these frameworks evolve, it is anticipated that the findings of this research will gain even greater relevance.

- Although the study indicates the overall beneficial effects of base flexibility, previous findings (Zareian and Kanvinde 2013) suggest that to reduce the incidence of soft-stories (especially for first-mode dominated structures), strong-column-weak-girder provisions (AISC 2016a) may need to be revisited, to adjust the point of inflection to account for base connection flexibility. This is in line with recent studies related to the influence of the composite action on the collapse capacity of steel MRFs (Elkady and Lignos 2014).

In discussing these potential implications, it is important to emphasize that the research does not recommend design considerations, but rather indicates physical mechanisms and their quantitative effects that must be considered in support of such considerations. These mechanisms involving the interactions of local and LTB are inherently complex, may be incorporated either by CFE simulations (as done in this study), or by modifying hinge/frame element properties based on the functional relationships determined in this study (e.g., as shown in Figures 3, 9, 12, 13).

embedded into concrete footings. The column base connections were considered to be capacity-designed (foundation designed to remain elastic and concentrate plastic deformation in the column) in accordance with the current design practice. The CFE simulations were based on a finite element model validated 
471 against full-scale physical tests of steel columns. The CFE model was refined to represent the actual

472 boundary conditions of columns in steel MRFs. In particular, the column base flexibility, $\beta$ was considered

473 based on measured values from prior embedded column base connection full-scale experiments. The column

474 top end boundary was properly refined to represent the in-plane and out-of-plane flexibilities of the

475 respective members intersecting the column. The torque demands imposed to the column after the beam-to-

476 column connection plastification were idealized with a drift-dependent relationship established based on

477 prior test observations. The CFE simulation matrix included variations in the applied compressive axial load

478 ratio $P / P_{y}$, the imposed loading history (monotonic versus symmetric cyclic), the cross-section and member

479 length, $L$ as well as the assumed degree of column base flexibility, $\beta$.

480 As expected, the actual (versus fixed) column base flexibility reduces the lateral stiffness of the base moment

$481-$ column drift relationship. In turn, this delays local buckling initiation (i.e., increases the rotation, $\theta^{*}{ }_{\max }$ or

$482 \theta_{\max }$, at the peak load), thereby delaying the cyclic deterioration in flexural strength of the steel column as

483 well as the initiation of axial shortening. If the best estimate of base flexibility is considered in the CFE

484 model, then the column's deformation capacity at the peak moment is increased, on average, by up to about

$48540 \%$ for the expected range of compressive axial load ratios in first story steel MRF columns $\left(P / P_{y} \leq 0.20\right)$.

486 The CFE simulations indicate that a greater increase can be achieved in $\theta^{*}{ }_{\max }$ if a more flexible base is

487 considered. The peak moment, $M^{*}{ }_{\max }\left(\right.$ or $M_{\max }$ ) and post-capping plastic rotation, $\theta_{p c}^{*}$ (or $\theta_{p c}$ ) are found to

488 be insensitive to the degree of column base flexibility for all the investigated cases.

489 Wide-flange steel columns assumed designed to be weaker than the base connection, and therefore assumed

490 to be ideally fixed (according to the current seismic design and simulation practice) experience considerable

491 flexural strength deterioration at modest lateral drift demands $(\sim 1.5 \%$ to $2 \%)$ when $L / L_{p}$ exceeds unity

492 (where $L_{p}$, which is indicative of the column resistance to LTB, is determined as per AISC 2016a). This is

493 attributed to coupling of local and lateral-torsional buckling. On the other hand, the same columns with the

494 true representation of the column base flexibility exhibit a positive trend with respect to $L / L_{p}$ such that a

495 greater benefit is obtained in members more susceptible to out-of-plane instabilities. An increase in the 
column base flexibility delays the formation of column plastic hinging near its base, and subsequently the loss of torsional fixity at the column's ends. This benefit diminishes for columns with $L / L_{p}<1$, with stocky cross sections that are less susceptible to lateral instability in the first place

The CFE simulations underscore the strong influence of the degree of column base flexibility on the resultant column axial shortening, which is an instability failure mode currently not addressed in seismic code provisions. In particular, steel columns with seismically compact cross-sections near the current classification limits as per the AISC (2016b) seismic provisions shorten considerably when idealized as fixed. This varies considerably depending on the considered degree of the base flexibility. At a reference lateral drift demand of $2 \%$ (indicative of a design basis earthquake) first story steel MRF columns with an assumed 50\% 'Actual' degree of base flexibility attains nearly zero residual axial shortening. This may have direct implications in reparability of steel MRF columns in the aftermath of earthquakes.

The CFE simulations indicate that in the range of $L / L_{p}<1.5$, columns with similar $L / L_{p}$ values ( $\operatorname{similar} r_{y}$ ) experience a sudden increase of axial shortening. This implies that for a given compressive axial load ratio $P / P_{y}$, the web slenderness ratio, $h / t_{w}$ primarily controls axial shortening. On the other hand, columns with $L / L_{p}>1.5$ are mainly governed by out-of-plane deformations, which does not result in excessive axial shortening. The above findings are consistent with observations from physical testing on deep wide-flange steel columns (Elkady and Lignos 2018a; Ozkula et al. 2017).

513 The CFE simulations confirm given the column base flexibility and loading history, empirical expressions 514 (Elkady and Lignos 2018b) provide good estimates of column axial shortening. This is because axial shortening (produced by irreversible local buckling deformations) is directly related to the cumulative plastic rotation demands in the column plastic hinge region. The present work indicates that embedded

517 column base connections with some degree of flexibility relative to the fixed-base assumptions (either 518 incidental - as in the case of existing buildings, or intentional - in the case of prospective buildings) improves 519 the overall seismic stability, as well as reparability of wide-flanged steel columns. These potential benefits shall be interpreted in the context of the limitations of this study, which are now briefly summarized. First, 
521 it is important to recognize that these effects have been observed only in CFE simulations and not system

522 or sub-system tests with realistic boundary conditions - albeit the simulations themselves have been

523 rigorously validated to capture the relevant physical phenomena. In fact, this study provides motivation for

524 the experimental confirmation of these effects. Second, in this paper, the base flexibility is idealized as a

525 single-degree-of-freedom rotational flexibility. In reality, connection details (e.g., reinforcement

526 attachments to the embedment, thickness of embedded base plates etc.,) may influence other aspects of

527 connection boundary condition such as warping restraint or translational flexibility. Finally, the analyses

528 conducted in this study only examine the effect of in-plane loading, whereas first story columns in MRFs

529 (even in planar frames) are often subjected to biaxial bending under multidirectional earthquake shaking.

530 However, this limitation persists even in current simulation practice with fixed bases, wherein frames are

531 seldom modeled in three dimensions. Future research is required to explore these limitations more fully.

532 Notwithstanding these limitations, this study provides compelling evidence that if incorporated

533 appropriately within current assessment techniques for performance based design (FEMA P695), simulation

534 of the effects of column base connection flexibility offers significant potential benefits in terms of steel

535 frame building performance.

536

537 Acknowledgments

538 This study is based on work supported by the Swiss National Science Foundation (Award No. 539 200021_169248). The financial support is gratefully acknowledged. Any opinions, findings, and 540 conclusions or recommendations expressed in this paper are those of the authors and do not necessarily 541 reflect the views of sponsors.

\section{References}

544 ABAQUS. (2014). ABAQUS analysis user's manual version 6.14-1. Dassault Systems Simulia Corp., RI, $545 \quad$ USA. 
AISC. (2016a). Seismic Provisions for Structural Steel Buildings. ANSI/AISC-341-16. American Institute of Steel Construction.

AISC. (2016b). Specification for Structural Steel Buildings. ANSI/AISC 360-16. American Institute of Steel Construction.

ASTM. (2017). A6/A6M - 17a: Standard Specification for General Requirements for Rolled Structural Steel Bars, Plates, Shapes, and Sheet Piling. American Society for Testing and Materials.

Barnwell, N. (2015). "Experimental Testing of Shallow Embedded Connections Between Steel Columns and Concrete Footings." All Theses and Dissertations.

BCJ. (2016). Building standard law of Japan. Building Center of Japan, Tokyo.

Castelo, M. V., Rodas, P. T., Zareian, F., and Kanvinde, A. M. (2017). "Seismic Performance of WeakBase Strong Column Steel Moment Frames.” 16th World Conference on Earthquake, Santiago Chile.

CEN. (2004). "Eurocode 8 Design of structures for earthquake resistance Part 1: General rules, seismic actions and rules for buildings."

Chi, B., and Uang, C. M. (2002). "Cyclic Response and Design Recommendations of Reduced Beam Section Moment Connections with Deep Columns.” Journal of Structural Engineering, 128(4), $464-473$.

Clark, P. W., Frank, K., Krawinkler, H., and Shaw, R. (2002). Protocol for Fabrication, Inspection, Testing

Cravero, J., Elkady, A., and Lignos, D. G. (2018). "Large scale tests on wide-flange steel columns under monotonic and cyclic drift coupled with constant and varying axial load, Journal of Structural Engineering (under review)." and Documentation of Beam-colum Connection Tests and Other Experimental Specimens. SAC Joint Venture.

Elkady, A., and Lignos, D. G. (2014). "Modeling of the composite action in fully restrained beam-to-column connections: implications in the seismic design and collapse capacity of steel special moment frames.” Earthquake Engineering \& Structural Dynamics, 43(13), 1935-1954. 
572 Elkady, A., and Lignos, D. G. (2015a). "Analytical investigation of the cyclic behavior and plastic hinge 573 formation in deep wide-flange steel beam-columns." Bulletin of Earthquake Engineering, 13(4), $574 \quad 1097-1118$.

575 Elkady, A., and Lignos, D. G. (2015b). "Effect of gravity framing on the overstrength and collapse capacity 576 of steel frame buildings with perimeter special moment frames." Earthquake Engineering \& Structural Dynamics, 44(8), 1289-1307.

578 Elkady, A., and Lignos, D. G. (2018a). "Full-Scale Testing of Deep Wide-Flange Steel Columns under Multiaxis Cyclic Loading: Loading Sequence, Boundary Effects, and Lateral Stability Bracing Force Demands.” Journal of Structural Engineering, 144(2), 04017189.

Elkady, A., and Lignos, D. G. (2018b). "Improved Seismic Design and Nonlinear Modeling Recommendations for Wide-Flange Steel Columns.” Journal of Structural Engineering, 144(9), 04018162.

FEMA. (2009). Quantification of building seismic performance factors. FEMA P695, Washington, DC.

Fisher, J., and Kloiber, L. (2006). "Base plate and anchor rod design, steel design guide 1, 2nd edition."

Fogarty, J., and El-Tawil, S. (2016). "Collapse Resistance of Steel Columns under Combined Axial and Lateral Loading.” Journal of Structural Engineering, 142(1), 04015091.

Fogarty, J., Wu, T. Y., and El-Tawil, S. (2017). "Collapse Response and Design of Deep Steel Columns Subjected to Lateral Displacement.” Journal of Structural Engineering, 143(9), 04017130.

Grilli, D. A., Jones, R., and Kanvinde, A. M. (2017). "Seismic Performance of Embedded Column Base Connections Subjected to Axial and Lateral Loads.” Journal of Structural Engineering, 143(5), 04017010 .

Grilli, D. A., and Kanvinde, A. M. (2015). "Final Report (3-11) Embedded Column Base Connections Subjected to Flexure and Axial Load: Tests and Strength Models." Department of Civil and Environmental Engineering University of California, DAVIS, CA 95616.

Grilli, D. A., and Kanvinde, A. M. (2017). "Embedded column base connections subjected to seismic loads: Strength model." Journal of Constructional Steel Research, 129, 240-249. 
Gupta, A., and Krawinkler, H. (1998). "Seismic demands for the performance evaluation of steel moment resisting frame structures." $\mathrm{PhD}$ Thesis, Stanford University.

Hamburger, R., Deierlein, G., Lehman, D., Lowes, L., Shing, B., Van de Lindt, J., Lignos, D., and Hortacsu, A. (2016). “ATC-114 Next-Generation Hysteretic Relationships for Performance-based Modeling and Analysis." Proceedings of the SEAOC Convention, Structural Engineers Association of California.

Ibarra, L. F., and Krawinkler, H. (2005). Global collapse of frame structures under seismic excitations. Pacific Earthquake Engineering Research Center Berkeley, CA.

Ibarra, L., and Krawinkler, H. (2011). "Variance of collapse capacity of SDOF systems under earthquake excitations.” Earthquake Engineering \& Structural Dynamics, 40(12), 1299-1314.

Krawinkler, H. (2009). "Loading Histories for Cyclic Tests in Support of Performance Assessment of Structural Components.” $\quad<$ paper/Loading-Histories-for-Cyclic-Tests-in-Support-of-ofKrawinkler/746da78be1d328c49ee7683143a6a0bb1d4380d5> (Aug. 6, 2018).

Lemaitre, J., and Chaboche, J.-L. (1994). Mechanics of solid materials. Cambridge university press.

Lignos, D. G., Hartloper, A. R., Elkady, A. M. A., Hamburger, R., and Deierlein, G. (2018). "Revised ASCE-41 modeling recommendations for moment-resisting frame systems." Proceedings of the 11th US National Conference on Earthquake Engineering (11NCEE).

Lignos, D. G., Hikino, T., Matsuoka, Y., and Nakashima, M. (2013). “Collapse Assessment of Steel Moment Frames Based on E-Defense Full-Scale Shake Table Collapse Tests." Journal of Structural Engineering, 139(1), 120-132.

Lignos, D. G., Kolios, D., and Miranda, E. (2010). "Fragility assessment of reduced beam section moment connections." Journal of Structural Engineering, 136(9), 1140-1150.

Lignos, D. G., and Krawinkler, H. (2012). “Development and utilization of structural component databases for performance-based earthquake engineering." Journal of Structural Engineering, 139(8), 13821394. 
Lignos, D. G., Krawinkler, H., and Whittaker, A. S. (2011). "Prediction and validation of sidesway collapse of two scale models of a 4-story steel moment frame." Earthquake Engineering \& Structural Dynamics, 40(7), 807-825.

Liu, J., and Astaneh-Asl, A. (2000). "Cyclic Testing of Simple Connections Including Effects of Slab.” Journal of Structural Engineering, 126(1), 32-39.

Liu, J., and Astaneh-Asl, A. (2004). "Moment-Rotation Parameters for Composite Shear Tab Connections." Journal of Structural Engineering, 130(9), 1371-1380.

MacRae, G. A., Carr, A. J., and Walpole, W. R. (1990). The Seismic Response of Steel Frames. Department of Civil Engineering, University of Canterbury, Christchurch, New Zealand.

Ozkula, G., Harris, J., and Uang, C.-M. (2017). “Observations from Cyclic Tests on Deep, Wide-Flange Beam-Columns.” Engineering Journal, 1, 45-59.

PEER-TBI. (2017). Guidelines for Performance-Based Seismic Design of Tall Buildings, prepared by the Tall Buildings Initiative Guidelines Working Group for the Pacific Earthquake Engineering Research Center. Pacific Earthquake Engineering Research Center (PEER), University of California, Berkeley.

Richards, P. W., Barnwell, N. V., Tryon, J. E., and Sadler, A. L. (2018). "Flexural strength and stiffness of block-out connections for steel columns.” Engineering Structures, 173, 404-415.

Rodas, P. T., Zareian, F., and Kanvinde, A. (2016). "Hysteretic Model for Exposed Column-Base Connections.” Journal of Structural Engineering, 142(12), 04016137.

Rodas, P. T., Zareian, F., and Kanvinde, A. (2017). "Rotational Stiffness of Deeply Embedded ColumnBase Connections.” Journal of Structural Engineering, 143(8), 04017064.

Sousa, A., and Lignos, D. G. (2018). On the inverse problem of classic nonlinear plasticity models -An application to cyclically loaded structural steels-. Technical Report No. 231968. Resilient Steel Structures Laboratory (RESSLab), École Polytechique Fédérale de Lausanne.

Suzuki, Y., and Lignos, D. (2018a). "Fiber-based model for earthquake-induced collapse simulation of steel frame buildings." Proceedings of the 11th US National Conference on Earthquake Engineering. 
649

Suzuki, Y., and Lignos, D. (2018b). "Improving the collapse risk of steel structures with high-performance steel." Proceedings of the 16th European Conference on Earthquake Engineering.

Suzuki, Y., and Lignos, D. G. (2014). “Development of Loading Protocols for Experimental Testing of Steel Columns Subjected to Combined High Axial Load and Lateral Drift Demands Near Collapse.” Proceedings of 10th National Conference on Earthquake Engineering (10th NCEE)Anchorage, Alaska, USA, 21-25.

Suzuki, Y., and Lignos, D. G. (2015). "Large Scale Collapse Experiments of Wide Flange Steel BeamColumns." Proceedings of the 8th International Conference on Behavior of Steel Structures in Seismic Areas (STESSA), Shanghai, China.

Trautner, C. A., Hutchinson Tara C., Grosser, P. R., and Silva, J. F. (2016). "Effects of Detailing on the Cyclic Behavior of Steel Baseplate Connections Designed to Promote Anchor Yielding.” Journal of Structural Engineering, 142(2), 04015117.

Voce, E. (1948). “The relationship between stress and strain for homogeneous deformation." Journal of the Institute of Metals, 74, 537-562.

Wu, T.-Y., El-Tawil, S., and McCormick, J. (2018). "Highly Ductile Limits for Deep Steel Columns." Journal of Structural Engineering, 144(4), 04018016.

Young, B. W. (1972). “Residual Stresses in Hot-Rolled Members.” proceedings of international colloquium on column strength.

Zareian, F., and Kanvinde, A. (2013). "Effect of Column-Base Flexibility on the Seismic Response and Safety of Steel Moment-Resisting Frames.” Earthquake Spectra, 29(4), 1537-1559.

Zhang, X., and Ricles, J. M. (2006). "Experimental Evaluation of Reduced Beam Section Connections to Deep Columns." Journal of Structural Engineering, 132(3), 346-357. 
673 Table 1. Summary of full-scale embedded column base connection test (Grilli et al. 2017)

674 (*minus sign indicates tensile force)

\begin{tabular}{cccccc}
\hline $\begin{array}{c}\text { Specimen } \\
\text { ID }\end{array}$ & $\begin{array}{c}\text { Cross- } \\
\text { section }\end{array}$ & $\begin{array}{c}P \\
(\mathrm{kN})\end{array}$ & $\begin{array}{c}d_{\text {embed }} \\
(\mathrm{mm})\end{array}$ & $\begin{array}{c}M_{\max , E C B} \\
(\mathrm{kNm})\end{array}$ & $\begin{array}{c}\beta \\
\left(10^{5} \mathrm{kNm} / \mathrm{rad}\right)\end{array}$ \\
\hline$\# 1$ & $\mathrm{~W} 14 \times 370$ & 445 & 508 & 2613 & 3.23 \\
$\# 2$ & $\mathrm{~W} 18 \times 311$ & 445 & 508 & 2324 & 3.84 \\
$\# 3$ & $\mathrm{~W} 14 \times 370$ & 0 & 762 & 3741 & 3.07 \\
$\# 4$ & $\mathrm{~W} 14 \times 370$ & 445 & 762 & 4124 & 3.38 \\
$\# 5$ & $\mathrm{~W} 14 \times 370$ & $-667^{*}$ & 762 & 3800 & 3.25 \\
\hline
\end{tabular}

675

676

677 
678 Table 2. Test Specimens used for FE model validation (Test data from Elkady and Lignos 2018a)

\begin{tabular}{cccccccc}
\hline $\begin{array}{c}\text { Specimen } \\
\text { ID }\end{array}$ & $\begin{array}{c}\text { Cross- } \\
\text { section }\end{array}$ & $P / P_{y}$ & $\begin{array}{c}\text { Boundary } \\
\text { Conditions } \\
\text { (Bottom-Top) }\end{array}$ & $L_{b} / r_{y}$ & $h / t_{w}$ & $\begin{array}{c}M_{\max } \\
(\mathrm{kNm})\end{array}$ & $\begin{array}{c}E I / L \\
\left(10^{5} \mathrm{kNm} / \mathrm{rad}\right)\end{array}$ \\
\hline C1 & W24x146 & $20 \%$ & Fixed-Fixed & 51.7 & 33.3 & 2913 & 0.923 \\
C2 & W24x146 & $50 \%$ & Fixed-Fixed & 51.5 & 33.1 & 2173 & 0.923 \\
C3 & W24x146 & $20 \%$ & Fixed-Flexible & 51.5 & 33.5 & 2907 & 0.923 \\
C7 & W24x84 & $20 \%$ & Fixed-Flexible & 79.2 & 47.0 & 1390 & 0.488 \\
\hline
\end{tabular}

679

680 
681 Table 3. Simulation matrix (total 2160 cases)

\begin{tabular}{ccccc}
\hline Column base rotational stiffness, $\beta$ & Length, $L$ & $\begin{array}{c}\text { Axial load ratio, } \\
P / P_{y}\end{array}$ & Cross-section & Lateral loading protocol \\
\hline 5 cases & 3 cases & 4 cases & 18 cases & 2 cases \\
(Fixed, Actual, 75\%Actual, 50\%Actual, & $\begin{array}{c}(3.0 \mathrm{~m}, 4.5 \mathrm{~m}, \\
\text { Pin) }\end{array}$ & $\begin{array}{c}(5,0 \mathrm{~m}) \\
\text { (see Fig. 8) }\end{array}$ & $\begin{array}{c}\text { (Monic, Symmetric } \\
\text { cyclic) }\end{array}$ \\
\hline
\end{tabular}

682

683

684 


\section{Figure Caption List}

686 Fig. 1. Illustration of collapse mechanisms of MRFs: (a) Soft-story mechanism, and (b) full-frame yielding 687 sway mechanism

688 Fig. 2. Details of typical embedded column base connections in United States

689 Fig. 3. Effect of flexible base on the cyclic response of steel columns (color indicates cumulative equivalent 690 plastic strain) $\left[\mathrm{W} 36 \times 529, L=6000 \mathrm{~mm}, P / P_{y}=35 \%\left(h / t_{w}=21, L_{b} / r_{y}=59\right)\right]$

691 Fig. 4. FE model validation with full-scale test specimens in base moment - column drift relation: (a) C1, 692 (b) C2, (c) C3, and (d) C7 (Test data from Elkady and Lignos 2018a)

693 Fig. 5. FE model validation with full-scale test specimens in axial shortening - absolute column drift relation:

694 (a) C1, (b) C2, (c) C3, and (d) C7 (Test data from Elkady and Lignos 2018a)

695 Fig. 6. Boundary conditions and applied forces in developed finite element model

696 Fig. 7. Torque force demand on the column due to local buckling within the steel beam RBS region

697 Fig. 8. Selected steel column cross-sections for the parametric study

698 Fig. 9. Effect of the column base flexibility on (a) base moment - column drift relation, (b) inflection point $699-$ absolute column drift relation, (c) vertical displacement - absolute column drift relation and (d) deformed 700 shape at $2^{\text {nd }}$ cycle of the $2 \%$ column drift amplitude (color indicates cumulative equivalent plastic strain) in 701 the representative case (W24x146, $L=4500 \mathrm{~mm}, P / P_{y}=20 \%, \beta=$ Fixed or Actual) under cyclic loading

702 Fig. 10. Disaggregation of the column drift (W24x146, $L=4500 \mathrm{~mm}, P / P_{y}=20 \%$, Cyclic loading): (a) $\beta=$ $703 \quad$ Fixed and (b) $\beta=$ Actual

704 Fig. 11. Schematic representation of primary column performance indicators: (a) Monotonic load case; (b) 705 Cyclic load case

706 Fig. 12. Monotonic curves obtained from three different cross-sections with different column base 707 flexibilities $\left(L=4500 \mathrm{~mm}, P / P_{y}=20 \%\right.$, monotonic loading)

708 Fig. 13 First cycle envelope curves obtained from three different cross-sections with different column base 709 flexibilities $\left(L=4500 \mathrm{~mm}, P / P_{y}=20 \%\right.$, Cyclic loading) 
711 Fig. 14. (a-b) Capping rotation, $\theta^{*}{ }_{\max }$ or (c-d) capping rotation, $\theta^{*}{ }_{\max }$ normalized by that attained in fixed

712 base case, $\theta^{*}{ }_{\text {max }}$,Fixed vs column length normalized by the limiting laterally unbraced length, $L / L_{p}$ relation 713 under cyclic loading. Data from (a) Fixed base, $P / P_{y}=20 \%$, (b) Fixed base, $P / P_{y}=50 \%$, (c) $L=4.5 \mathrm{~m}, P / P_{y}$ $714=20 \%$, and (d) $L=4.5 \mathrm{~m}, P / P_{y}=50 \%$

715 Fig. 15. Definition of column axial shortening

716 Fig. 16. Column axial shortening vs (a) web local slenderness, $h / t_{w}$ (expressed as function of column base 717 flexibility) (data from $L=4500 \mathrm{~mm}, P / P_{y}=20 \%$, cyclic loading cases) and (b) column length normalized 718 by the limiting laterally unbraced length, $L / L_{p}$ (data from Fixed base, $P / P_{y}=20 \%$, cyclic loading cases, at $719 \quad 1^{\text {st }} 4 \%$ positive excursion)

720 Fig. 17. Vertical displacement - Cumulative plastic rotation relation obtained from four different cross721 sections (W36x194, W24x146, W21x147, W14x221) with different column base flexibilities $(L=4500 \mathrm{~mm}$, $722 \quad P / P_{y}=20 \%$ case $)$

723 Fig. 18. Cumulative plastic rotation - column drift relation obtained from cases W24x146, $L=4500 \mathrm{~mm}$, $724 P / P_{y}=20 \%$ with different column base flexibilities 


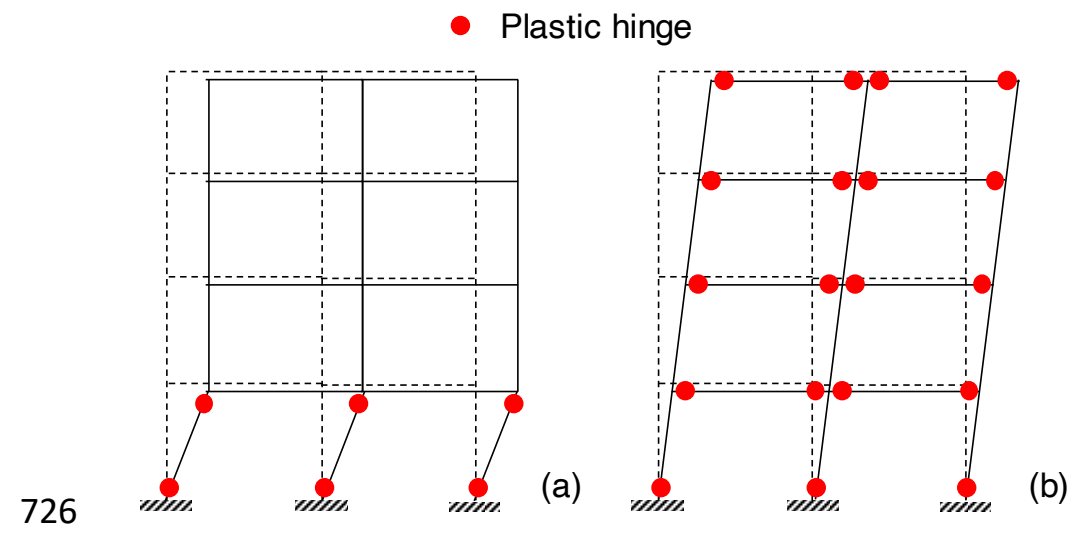

727 Fig. 1. Illustration of collapse mechanisms of MRFs: (a) Soft-story mechanism, and (b) full-frame yielding 728 sway mechanism 


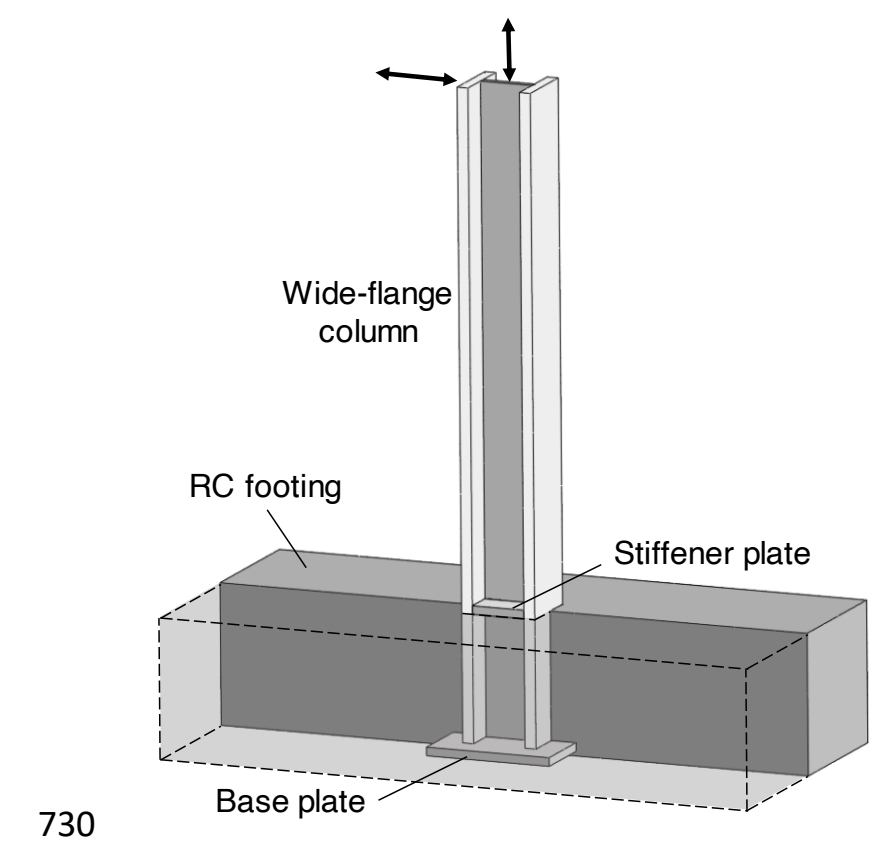

731 Fig. 2. Details of typical embedded column base connections in United States 732 


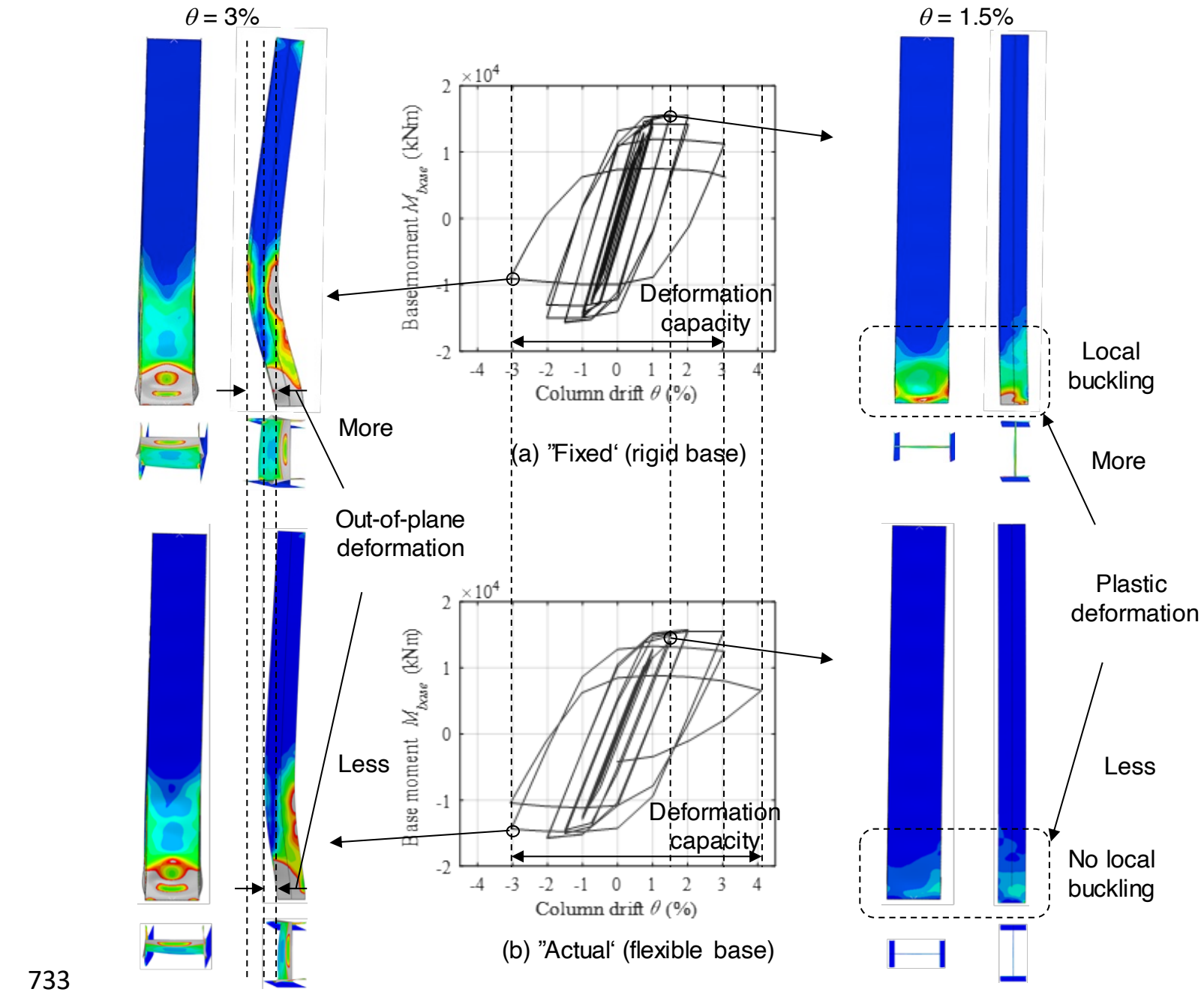

734 Fig. 3. Effect of flexible base on the cyclic response of steel columns (color indicates cumulative equivalent

735 plastic strain) $\left[\mathrm{W} 36 \times 529, L=6000 \mathrm{~mm}, P / P_{y}=35 \%\left(h / t_{w}=21, L_{b} / r_{y}=59\right)\right]$ 

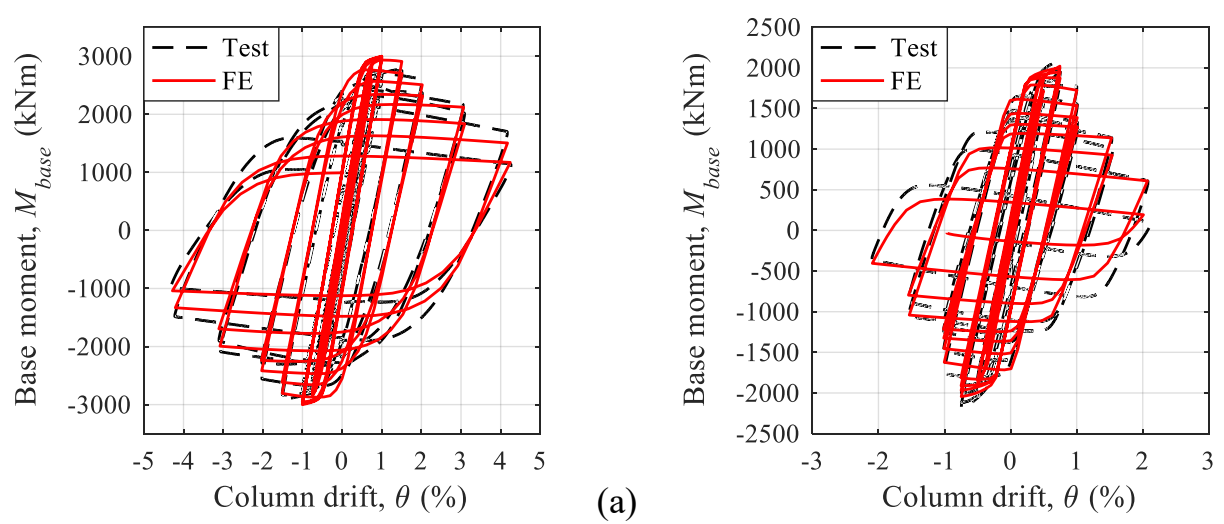

(b)

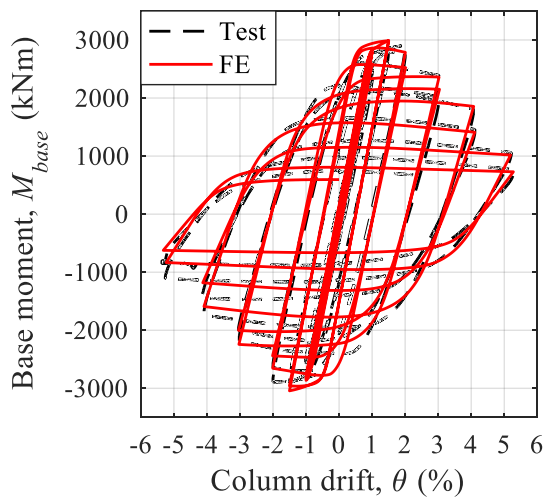

(a)

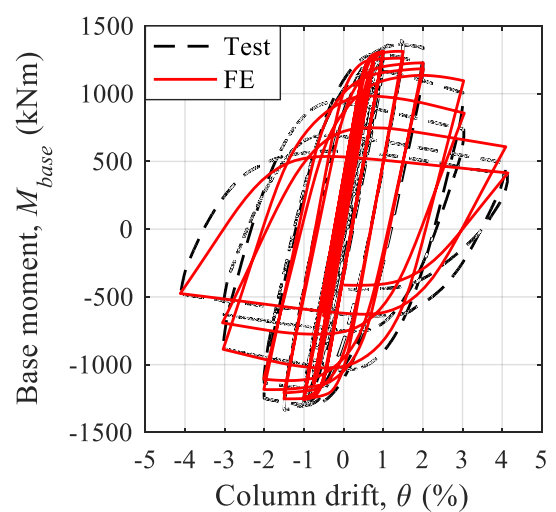

(c)

Column drift, $\theta(\%)$

(d)

737 Fig. 4. FE model validation with full-scale test specimens in base moment - column drift relation: (a) C1,

738 (b) C2, (c) C3, and (d) C7 (Test data from Elkady and Lignos 2018a) 

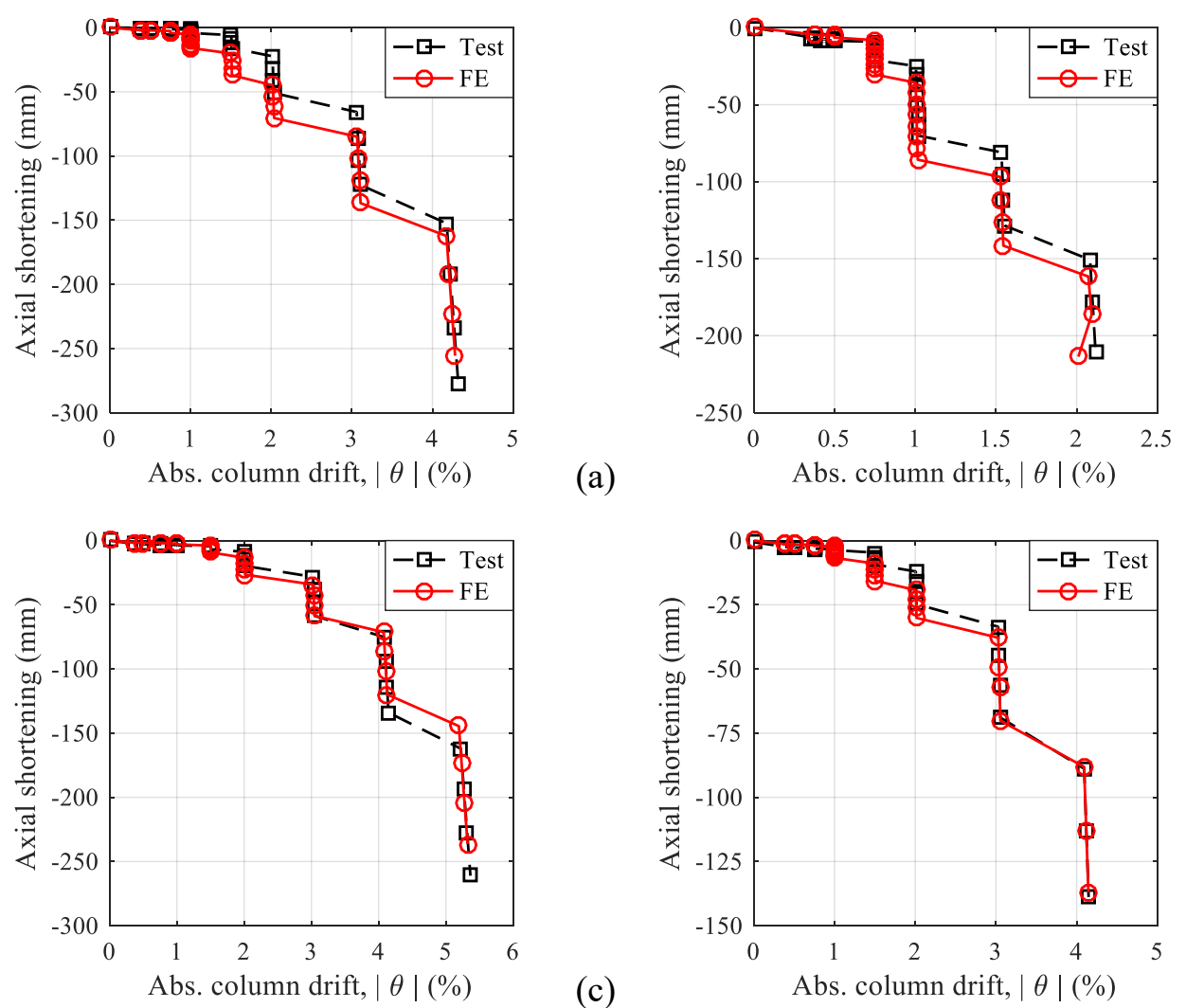

(a)

(b)

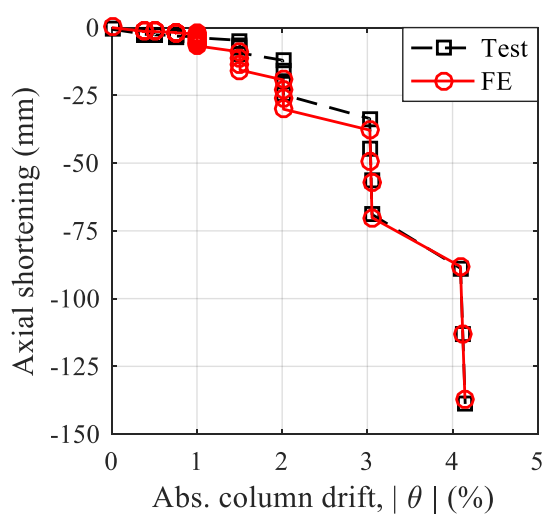

740 Fig. 5. FE model validation with full-scale test specimens in axial shortening - absolute column drift relation:

741 (a) C1, (b) C2, (c) C3, and (d) C7 (Test data from Elkady and Lignos 2018a)

742 


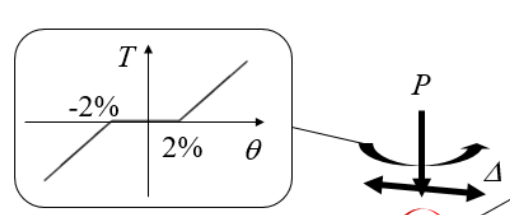

Torque by RBS local buckling

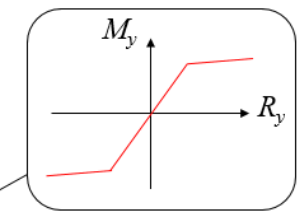

Spring (y-axis):

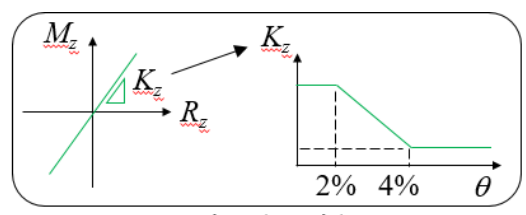

Spring (z-axis):

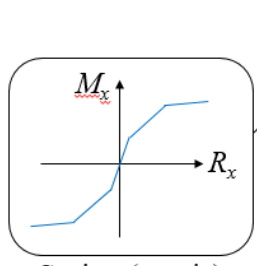

Girders

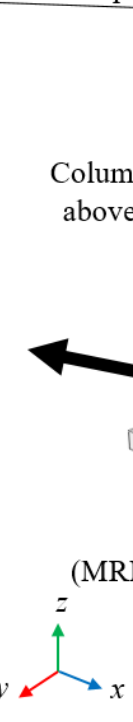

Shear tab + Girders + Column above

pring ( $x$-axis):

Shear tab + Girders

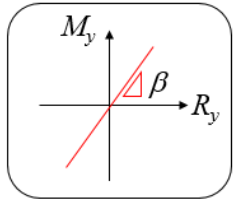

Spring ( $y$-axis):

Embedded Column Base

FE model boundary conditions

Fig. 6. Boundary conditions and applied forces in developed finite element model 


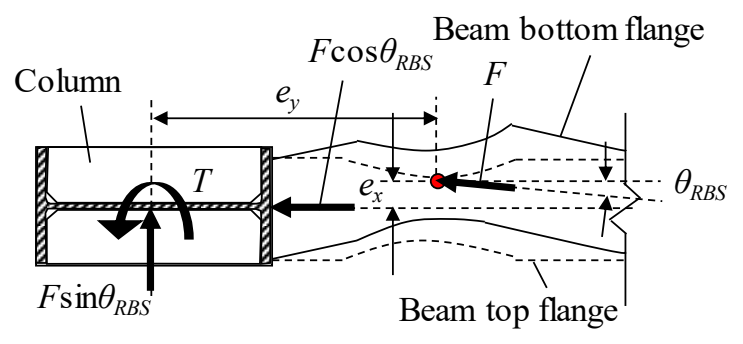

747 Fig. 7. Torque force demand on the column due to local buckling within the steel beam RBS region 


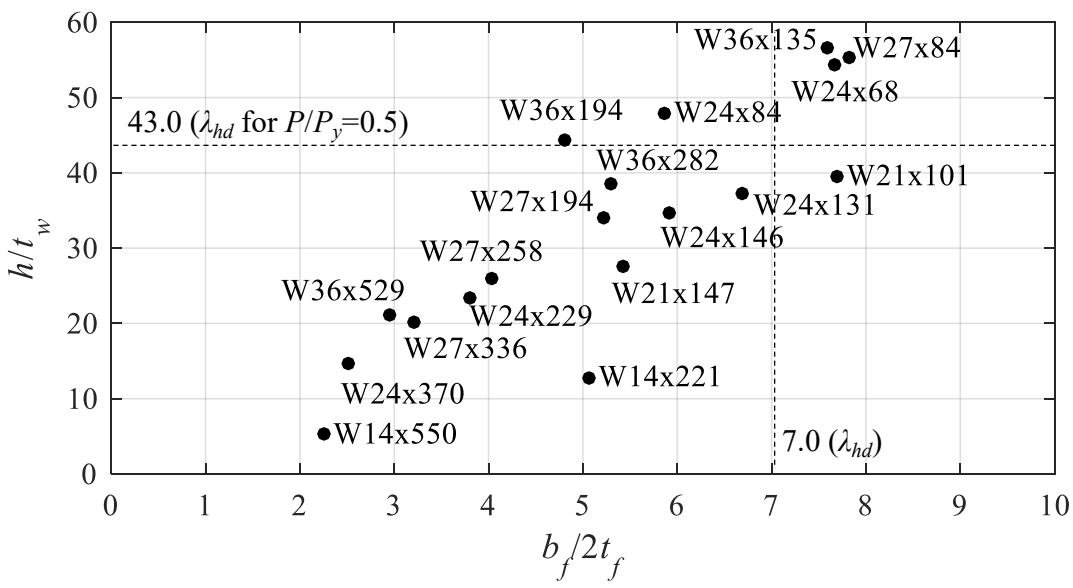

750 Fig. 8. Selected steel column cross-sections for the parametric study 


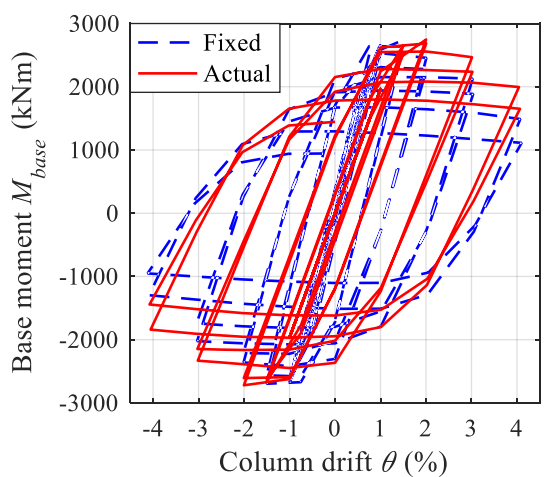

(a)

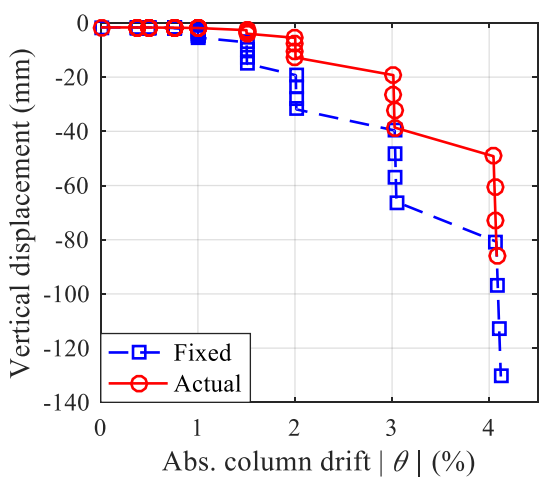

(c)

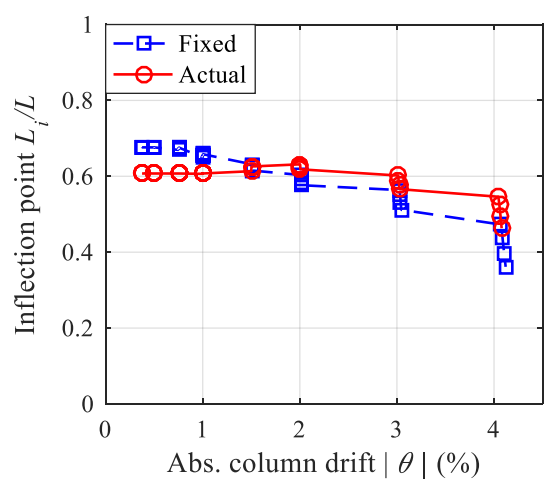

(b)
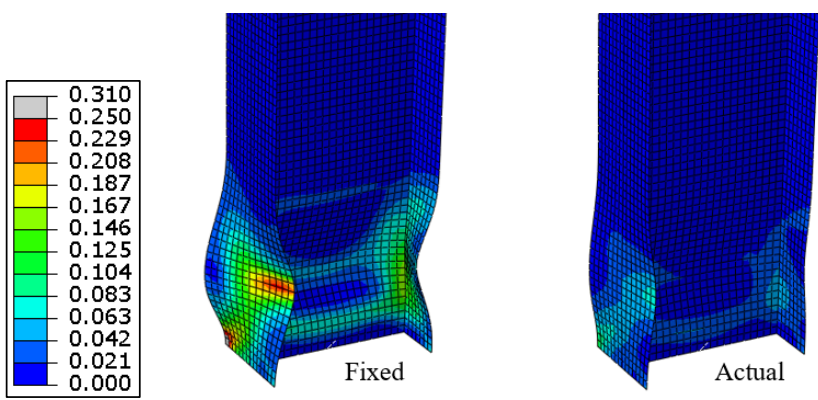

(d)

752 Fig. 9. Effect of the column base flexibility on (a) base moment - column drift relation, (b) inflection point

753 - absolute column drift relation, (c) vertical displacement - absolute column drift relation and (d) deformed

754 shape at $2^{\text {nd }}$ cycle of the $2 \%$ column drift amplitude (color indicates cumulative equivalent plastic strain) in

755 the representative case (W24x146, $L=4500 \mathrm{~mm}, P / P_{y}=20 \%, \beta=$ Fixed or Actual) under cyclic loading 

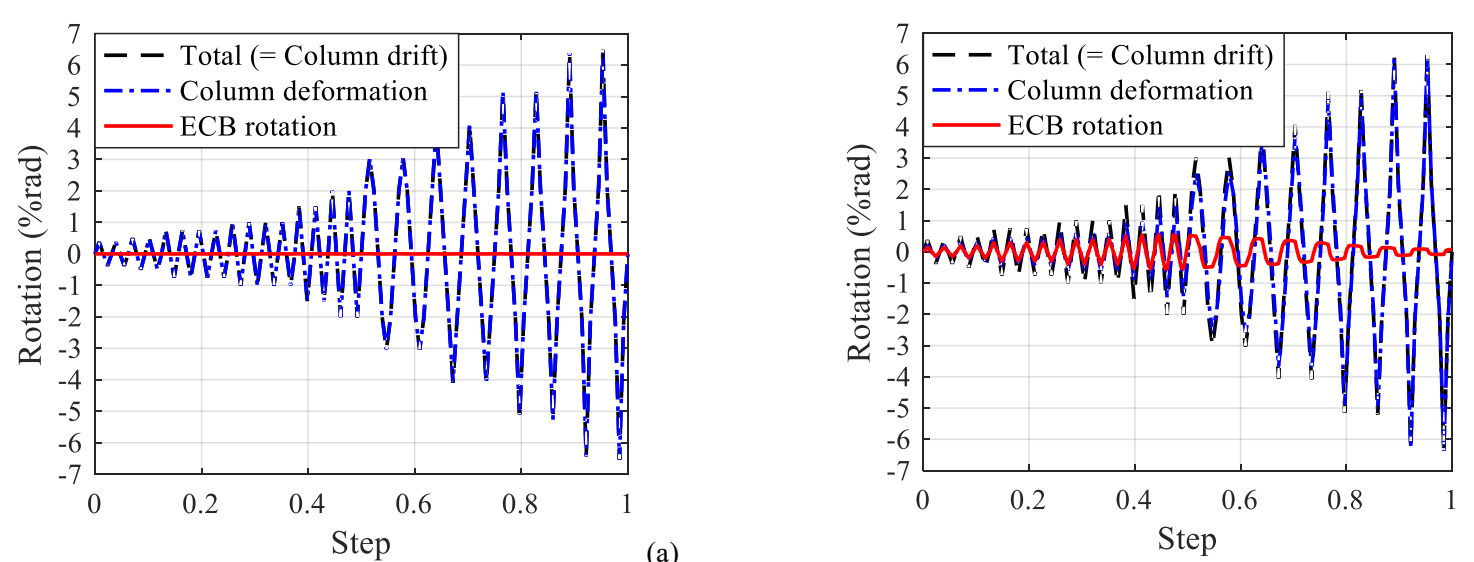

757 Fig. 10. Disaggregation of the column $\operatorname{drift}\left(\mathrm{W} 24 \mathrm{x} 146, L=4500 \mathrm{~mm}, P / P_{y}=20 \%\right.$, Cyclic loading): (a) $\beta=$

$758 \quad$ Fixed and (b) $\beta=$ Actual

759 

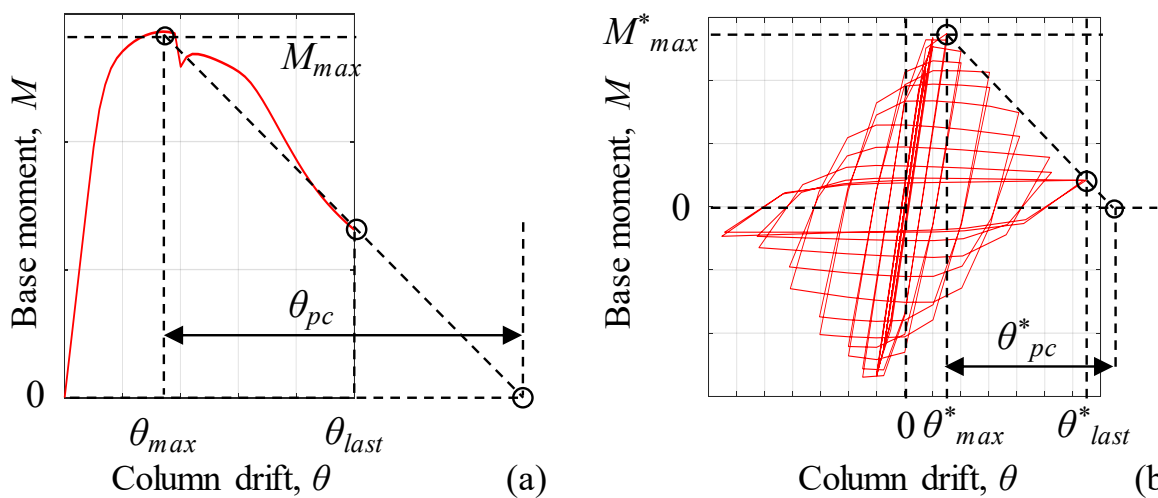

760

(a)

Column drift, $\theta$

(b)

761 Fig. 11. Schematic representation of primary column performance indicators: (a) Monotonic load case; (b)

762 Cyclic load case

763 


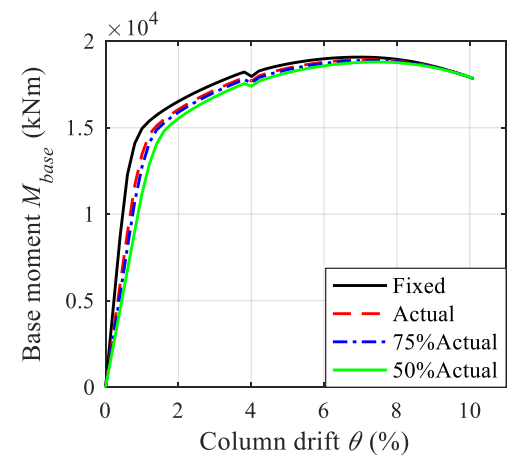

(a) $\mathrm{W} 36 \times 529\left(h / t_{w}=21\right)$

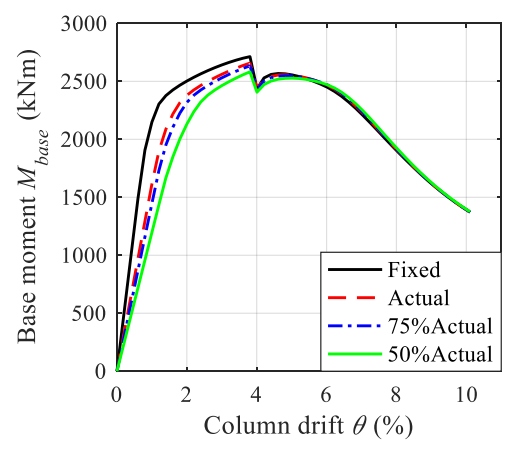

(b) $\mathrm{W} 21 \times 147\left(h / t_{w}=28\right)$

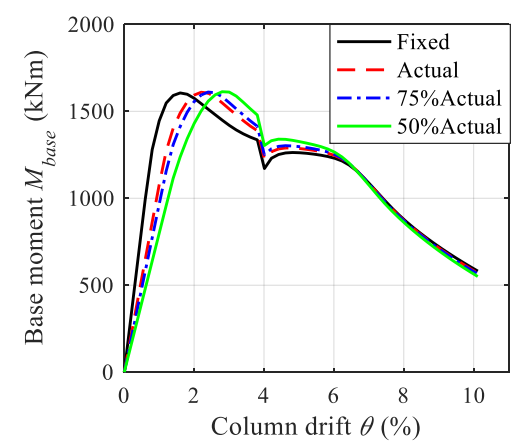

(c) W21x101 $\left(h / t_{w}=40\right)$

764 Fig. 12. Monotonic curves obtained from three different cross-sections with different column base

765 flexibilities ( $L=4500 \mathrm{~mm}, P / P_{y}=20 \%$, monotonic loading). 


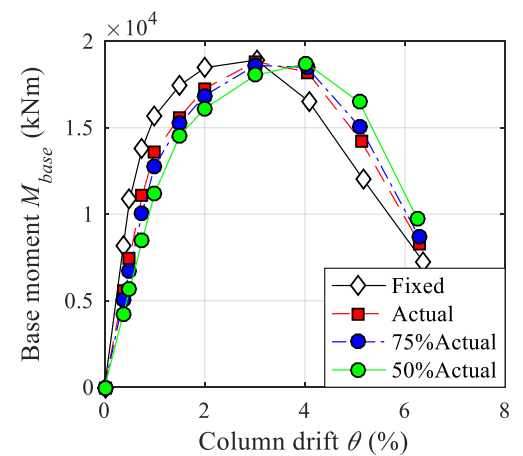

(a) $\mathrm{W} 36 \times 529\left(h / t_{w}=21\right)$

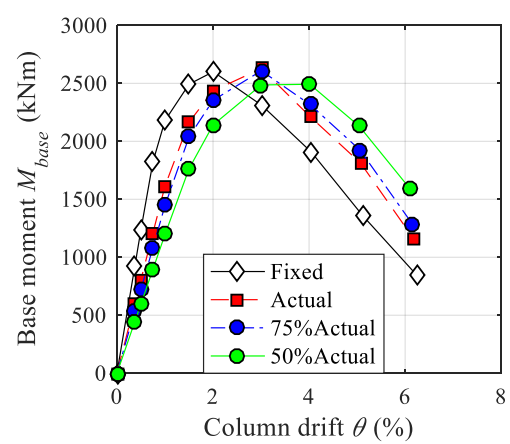

(b) $\mathrm{W} 21 \times 147\left(h / t_{w}=28\right)$

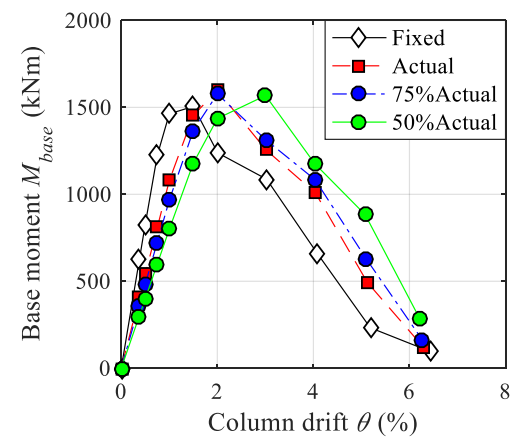

(c) $\mathrm{W} 21 \times 101\left(h / t_{w}=40\right)$

767 Fig. 13 First cycle envelope curves obtained from three different cross-sections with different column base

768 flexibilities ( $L=4500 \mathrm{~mm}, P / P_{y}=20 \%$, Cyclic loading). 

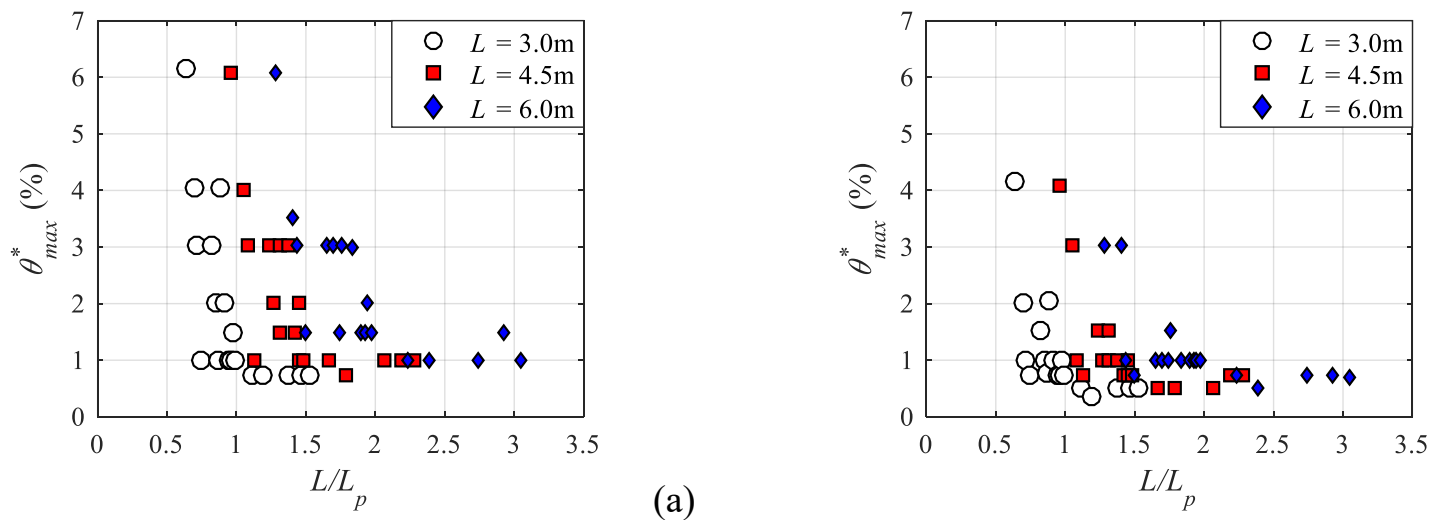

(b)
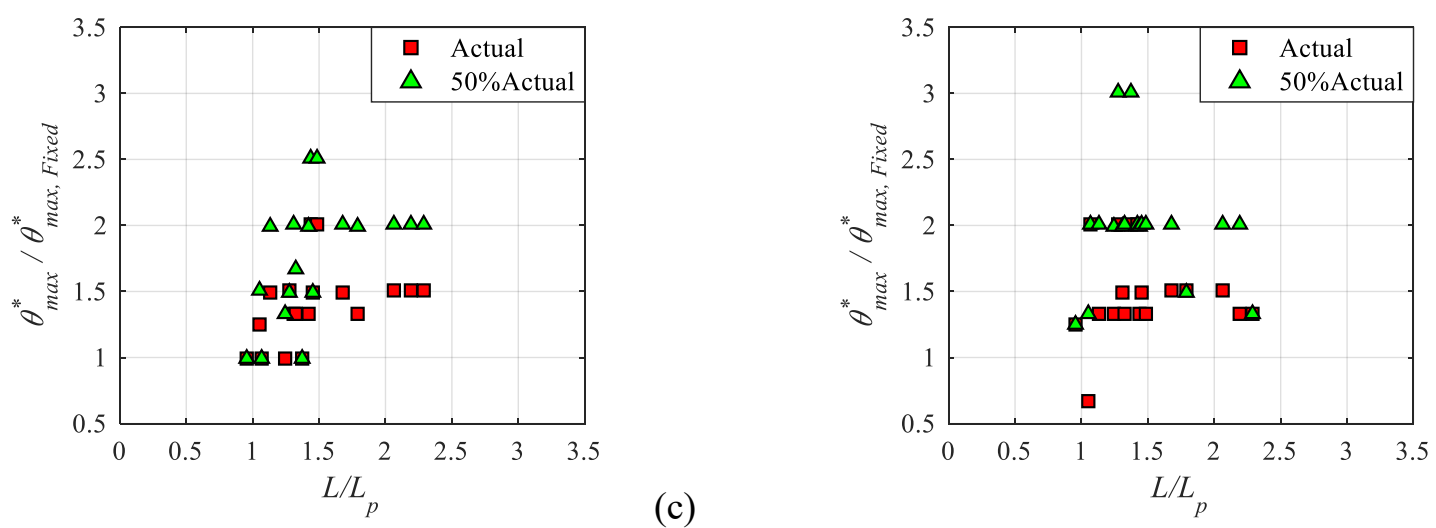

(d)

770 Fig. 14. (a-b) Capping rotation, $\theta^{*}{ }_{\max }$ or (c-d) capping rotation, $\theta_{\max }^{*}$ normalized by that attained in fixed

771 base case, $\theta_{\text {max, Fixed }}^{*}$ vs column length normalized by the limiting laterally unbraced length, $L / L_{p}$ relation

772 under cyclic loading. Data from (a) Fixed base, $P / P_{y}=20 \%$, (b) Fixed base, $P / P_{y}=50 \%$, (c) $L=4.5 \mathrm{~m}, P / P_{y}$

$773=20 \%$, and (d) $L=4.5 \mathrm{~m}, P / P_{y}=50 \%$. 


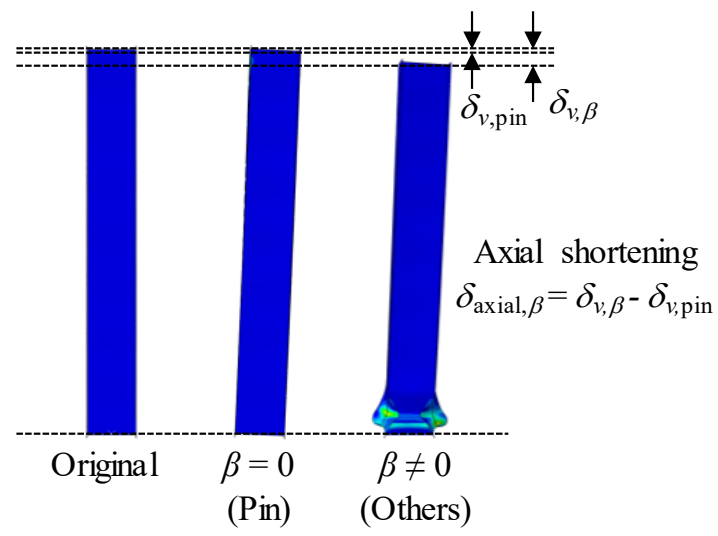

776 Fig. 15. Definition of column axial shortening 


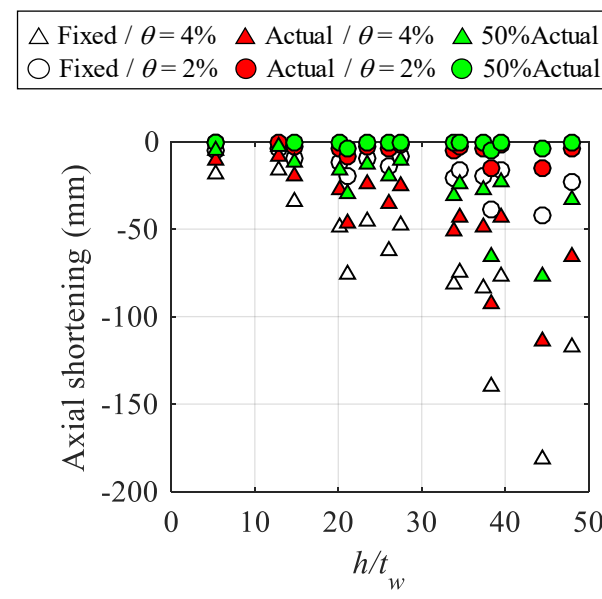

(a)

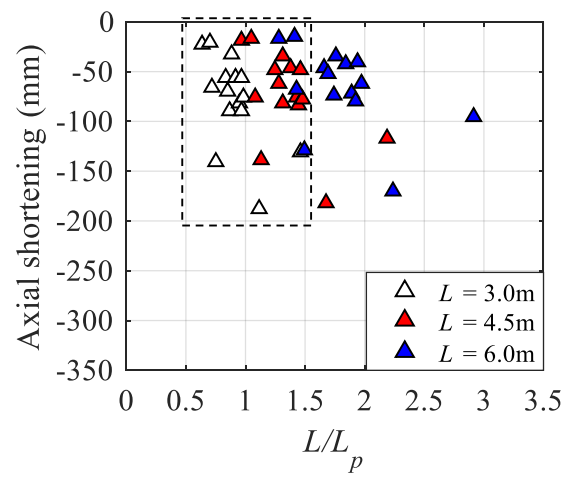

(b)

778 Fig. 16. Column axial shortening vs (a) web local slenderness, $h / t_{w}$ (expressed as function of column base 779 flexibility) (data from $L=4500 \mathrm{~mm}, P / P_{y}=20 \%$, cyclic loading cases) and (b) column length normalized 780 by the limiting laterally unbraced length, $L / L_{p}$ (data from Fixed base, $P / P_{y}=20 \%$, cyclic loading cases, at $781 \quad 1^{\text {st }} 4 \%$ positive excursion) 

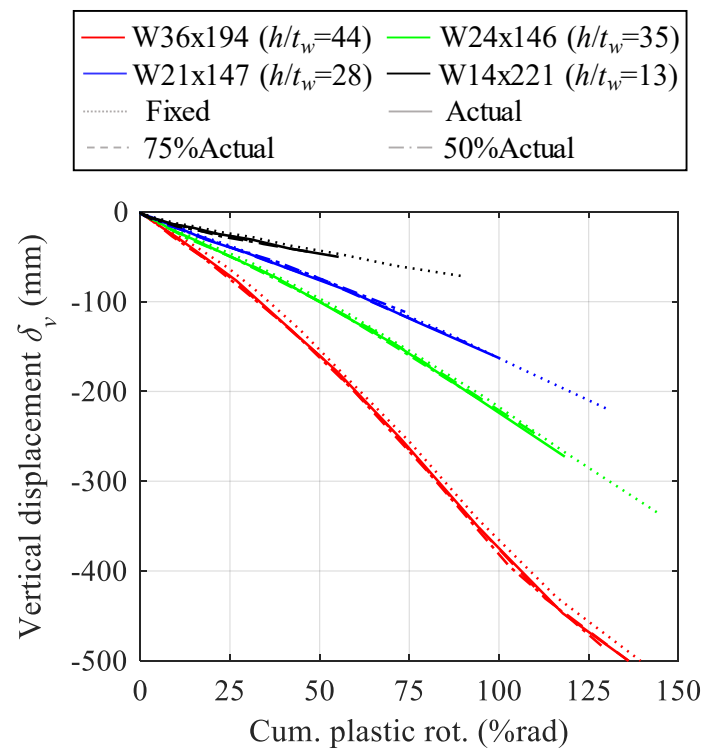

Fig. 17. Vertical displacement - Cumulative plastic rotation relation obtained from four different cross785 sections (W36x194, W24x146, W21x147, W14x221) with different column base flexibilities $(L=4500 \mathrm{~mm}$, $786 P / P_{y}=20 \%$ case $)$. 


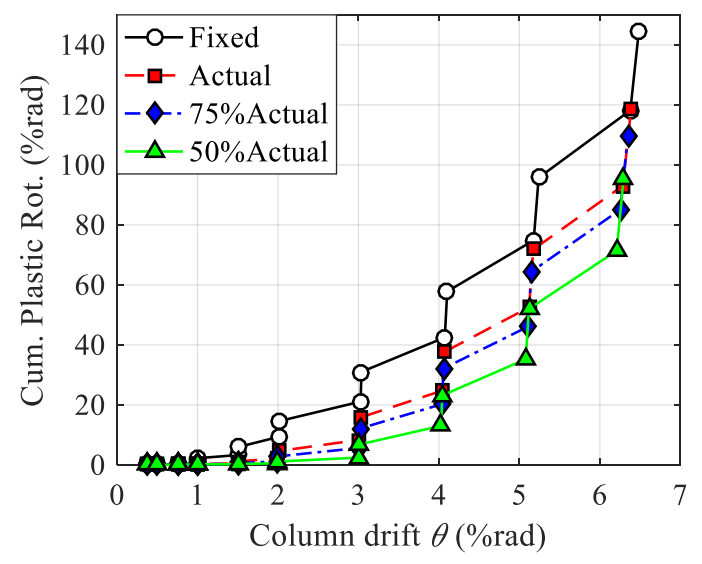

789 Fig. 18. Cumulative plastic rotation - column drift relation obtained from cases W24x146, $L=4500 \mathrm{~mm}$, $790 P / P_{y}=20 \%$ with different column base flexibilities. 